\title{
Accuracy of Wind Measurements Performed on Buoys, Ship, and Island during the TOSCANE-2 Experiment
}

\author{
PIERRE QUEFFEULOU \\ Institut Français de Recherche pour l'Exploitation de la Mer (IFREMER), Centre de Brest, France
}

(Manuscript received 4 October 1990, in final form 19 April 1991)

\begin{abstract}
In 1983 the project "Travaux d'Océanographie Spatiale: Capteurs Actifs dans l'Atlantique Nord-Est" (TOSCANE) was initiated in view of calibration, validation, and use of satelliteborne scatterometer and altimeter measurements in terms of wind and wave data, with special emphasis on the ERS-1 satellite to be launched in 1991 by the European Space Agency. The wind measurements from an array of buoys and ship and land stations, deployed during the last experiment within the program, TOSCANE-2, are described, and a method is given to evaluate their accuracy. When comparing wind data from two measuring stations at sea, the averaging time has to be selected according to the separation distance between the two locations to filter out the spaceinduced wind variability. For buoy and ship comparisons, for distances less than $3 \mathrm{~km}$, a 10 -min averaging time was found to be a lower limit. For pairs of buoys separated by 25 or $35 \mathrm{~km}$, the standard deviation of differences decreases with averaging time, in the same manner for speed and direction: by about $40 \%$ when passing from $10 \mathrm{~min}$ to $6 \mathrm{~h}$ averaging (from 1.3 to $0.8 \mathrm{~m} \mathrm{~s}^{-1}$ for speed, and from $14^{\circ}$ to $9^{\circ}$ for direction) with a plateau value (50\%) after $12 \mathrm{~h}$. Data from the two independent wind systems on board N/O Le Noroit show a high consistency: mean values of differences for direction and speed are $5.9^{\circ}$ and $0.29 \mathrm{~m} \mathrm{~s}^{-1}$, with standard deviations of $4.5^{\circ}$ and $0.40 \mathrm{~m} \mathrm{~s}^{-1}$, the standard deviation of speed differences increasing $\left(0.10\right.$ to $\left.0.49 \mathrm{~m} \mathrm{~s}^{-1}\right)$ over the $1-30 \mathrm{~m} \mathrm{~s}^{-1}$ speed range; $99.9 \%$ of data are within $\pm 2 \mathrm{~m} \mathrm{~s}^{-1}$. When calibrating anemometers with coefficients from wind tunnel tests, differences between buoy speeds are large, as much as $1.4 \mathrm{~m} \mathrm{~s}^{-1} \pm 0.8 \mathrm{~m} \mathrm{~s}^{-1}$, resulting from, among other causes, the inability of sensors to correctly filter high-frequency fluctuations of wind speed. The buoys were then tuned independently, relative to ship data from dedicated runs, which allowed a reduction of differences to maximum values of $0.5 \mathrm{~m} \mathrm{~s}^{-1} \pm 0.8 \mathrm{~m} \mathrm{~s}^{-1}$ and $4^{\circ} \pm 9^{\circ}$. These results are compatible with an assessment of the foreseen $2 \mathrm{~m} \mathrm{~s}^{-1}$ and $20^{\circ}$ accuracy of the $E R S-I$ scatterometer wind data. In contrast, wind data from a $10-\mathrm{m}$ mast on a flat island are shown not to be accurately representative of wind at sea, even for onshore wind
\end{abstract}

\section{Introduction}

In 1983 the project "Travaux d'Océanographie Spatiale: Capteurs Actifs dans l'Atlantique Nord-Est" (TOSCANE) was initiated at Institut Français de Recherche pour l'Exploitation de la Mer (IFREMER), in view of calibration, validation, and use of satelliteborne scatterometer and altimeter measurements, in terms of wind and wave data. Special emphasis was put on the European Earth Remote Sensing Satellite ( $E R S-1)$, to be launched in 1991 by the European Space Agency (ESA). Radar sea-echo models for scatterometer, relating the backscatter coefficient to the wind vector, are at present essentially empirical, mainly because of the complexity of the physics of interaction among the wind stress, the various scales of sea surface roughness, and the incident radar electromagnetic

Corresponding author address: Dr. Pierre Queffeulou, Institut Francais de Recherche pour l'Exploitation de le Mer (IFREMER), 29263 Plouzane, Centre de Brest, France. wave. Within this context, the TOSCANE group investigated two aspects. The first one was the development and test of wind and wave measuring devices at sea, and the evaluation of the accuracy of measurements. The second was the investigation of spatial and temporal scales of at-sea wind fluctuations in order to be able to use the classical in situ wind measurement, time-averaged data at a fixed location, to calibrate and validate the scatterometer backscatter coefficient measurement which is an average in space over the footprint ( $50 \times 50 \mathrm{~km}^{2}$ for the $E R S-1$ scatterometer) and in time over a very short duration (less than about 2 min, depending on the subsatellite track range). These two ways were investigated through in situ experiments performed in collaboration with ESA and other teams involved in wind and wave measurement at sea and satellite or aircraft radar techniques.

This paper presents the TOSCANE-2 experiment performed in November and December 1987 and the subsequent effort to evaluate the data quality of wind measurements from an array of buoys and ship and land stations. This campaign was the third one per- 
formed within the project and it is worth recalling the previous steps.

The first experiment, TOSCANE-1-PROMESS (Penmarc'h Radar Oceanographic Experiment on Signature Study) in February 1984, allowed a test and evaluation of a wind measurement procedure on board a dedicated ship (Ezraty and Queffeulou 1987). During the experiment, measurements were also collected from four airborne scatterometers flown by Max Plank Institut of Hamburg, Centre de Recherche de Physique de l'Environnement, Delft University of Technology, and Canada Centre for Remote Sensing, respectively. These data, together with ship data, allowed an estimation of the coefficients of an empirical model relating the C-band (frequency of the $E R S-1$ scatterometer) backscatter coefficient to the surface wind vector (Long 1985). A third result from this experiment was an insight in the correlation between weather stability conditions and large wind fluctuations ranging in time from a few minutes to one hour (Lavanant et al. 1985).

A second step was achieved during the TOSCANET experiment in 1985 (Groupe Toscane 1986). Seven instrumented wind masts were deployed along the Baie d'Audierne coastal site in Brittany together with two buoys moored $6 \mathrm{~km}$ west of the site. Aircraft measurements were also performed. From a technical point of view, operations and monitoring of the land-based network were satisfactory; an IFREMER buoy was tested and improved for some construction errors in the radio transmitter. Comparison of masts, CMM (Centre de Meteorologie Marine, Meteorologie Nationale) buoy data; and aircraft data (Daniault et al. 1988) showed that the three types of measurements were in reasonable agreement and that most of the differences observed between buoys and masts came from the buoy data truncation ( $1 \mathrm{kt}$ for speed and $10^{\circ}$ for direction ). Comparisons between aircraft and mast data were also shown to be delicate under meteorological conditions including convective clouds, as often found behind meteorological cold fronts over the North Atlantic Ocean. Furthermore, spectral analysis of the mast data showed (Champagne-Philippe 1989) that in such convective weather cases, the wind "spectral gap" in the transition region from turbulence to mesoscale disappeared. These situations are associated with cumulus and cumulonimbus clouds more or less organized in open mesoscale cells. The size of these cells is of the order of magnitude of the scatterometer footprint, which implies in such cases, for scatterometer calibration purpose, a careful choice of the averaging duration of surface data. The author also investigated the time and spatial structure of wind. The main result is that the averaged periods of decorrelation range from 10 to $20 \mathrm{~min}$ at distances from 1.5 to $8.5 \mathrm{~km}$.

The next logical step was to deploy a wind measurement network at sea covering the $25-50-\mathrm{km}$ spatial scales resolved by the ERS-1 scatterometer. This was achieved during the TOSCANE-2 experiment. The aim of this paper is to describe this experiment and to evaluate the quality of the wind measurements collected during this campaign from buoys, a ship, and an islandbased station, taking into account the interdependence between separation distances and time averaging. First the measuring network is described together with the operations within the experiment, data return, and meteorological conditions (section 2). General errors in wind measurements from the ship and buoys are discussed in section 3 , as are particular characteristics relevant to the experiment (anemometers, ship speed, airflow distortion by ship superstructures, effect of buoy motion induced by waves, and adjustment of wind speed data to a reference level). The two wind-measuring systems mounted on board the ship allowed an evaluation of the consistency of ship wind measurements (section 4), and then the buoy measurements were tested against ship data with emphasis on the influence of time averaging and separation distances (section 5). The buoys were then calibrated against ship data and tested through intercomparisons (section $6)$. Section 7 is devoted to the analysis of the island wind measurements in terms of sensors and land effects.

\section{Summary of surface experiment}

The experiment was conducted in November and December 1987, in the North Atlantic Ocean, west of the southern Brittany coast (Fig. 1). The experimental setup involved eight wind- and two wave-measuring stations, supported by seven buoys at sea and one mast on Sein Island. Surveys of the network and monitoring of meteorological parameters were achieved on board N/O Le Noroit, during the intensive part of the calmpaign (19 November to 6 December).

\section{a. At-sea in situ network}

The major axis of the network M1-M0-M2, was selected along the prevailing wind direction anticipated during the experiment period. The buoy array was centered on location M0 $\left(47^{\circ} 51^{\prime} 53^{\prime \prime} \mathrm{N}, 04^{\circ} 56^{\prime} 30^{\prime \prime} \mathrm{W}\right)$ such that the second axis was perpendicular to the previous one, and the network used the Sein Island as a land-based measuring station. The sizes of the network were $25 \mathrm{~km}$ for M0-M1, M0-M2, and M0-M3, and $20 \mathrm{~km}$ for M0-Sein. Location M0 was heavily instrumented ( see insert in Fig. 1) since one of the campaign goals was buoy wind data comparisons: Marisonde position refers to the CMM buoy, Tobis refers to the Norwegian Oceanor buoy, Spear-f is a wave spectrum buoy, and IFREMER is the position of buoy 5, a prototype instrumented with two independent wind-measuring systems. Buoys 6,7 , and 8 , located at M3, M1, and M2, respectively, were practically identical wind-rneasuring buoys; unfortunately, buoy 8 (M2) broke its mooring line a few days after being deployed and returned no data. 


\section{1) IFREMER PROTOTYPE BUOY 5}

This buoy (Fig. 2) was $12 \mathrm{~m}$ long and equipped with two independent wind measurement systems differing only by the wind sensors, mounted $5 \mathrm{~m}$ above sea level. The first one was the $05103 \mathrm{R}$. M. Young wind monitor: an integral horizontal axis propeller and vane. The second one was the three-cup anemometer and vane (Fig. 3) manufactured by Debucourt. The two SafareCrouzet fluxgate compasses were mounted near the top of the mast in order to avoid as much as possible the magnetic perturbation of the buoy. Nevertheless, they were calibrated before the experiment, the buoy being fully equipped. More details about sensors and preexperiment calibration tests can be found in Queffeulou et al. (1988). Data sampling and processing were achieved by Cactus electronics (Nereides, France) including a two-way VHF radio link for internal programming and data transmission; these electronics were already used during the TOSCANE-T campaign (Groupe Toscane 1986).

The wind vector sampling is described next. Over a fixed time period $T_{o}(3 \mathrm{~s})$, the number of pulses produced by the anemometer is counted. For instance, the Debucourt anemometer output is two pulses per rotor revolution. The passing wind distance between two pulses is a constant $(l)$, of the order of $30 \mathrm{~cm}$; its exact value is determined by calibration tests. For each pulse, the vane and compass information (compass data are averaged values over $3 \mathrm{~s}$ ) are sampled and components $\left(l \cos \theta_{i}, l \sin \theta_{i}\right)$ of the elementary covered distance are computed in the magnetic (east, north) reference frame, and then summed over the time period $T_{o}$. This information together with the number of pulses over $T_{o}$, expressed in frequency units $\left(n / T_{o}\right)$, is used to compute the average wind vector "frequency" components over $T_{o}$. In the last step, according to the station setting, wind vector components are averaged over a time period $T\left(T=N T_{o}\right)$. During the main phase of the TOSCANE-2 experiment, $T$ was set to $1 \mathrm{~min}$ for buoys and mast station and to $30 \mathrm{~s}$ for $\mathrm{N} / \mathrm{O}$ Le Noroit station; during the second part of the experiment (after day 340) $T$ was set to $2 \min 30 \mathrm{~s}$.

Thus, the available data are the average frequency components $(\mathrm{Ce}, \mathrm{Cn})$ of the wind vector over $T$. Direction and speed of wind vector are then computed as:

$$
\begin{aligned}
\text { direction } & =\arctan (\mathrm{Cn} / \mathrm{Ce}) \\
\text { speed } & =A\left(\mathrm{Ce}^{2}+\mathrm{Cn}^{2}\right)^{1 / 2}+B,
\end{aligned}
$$

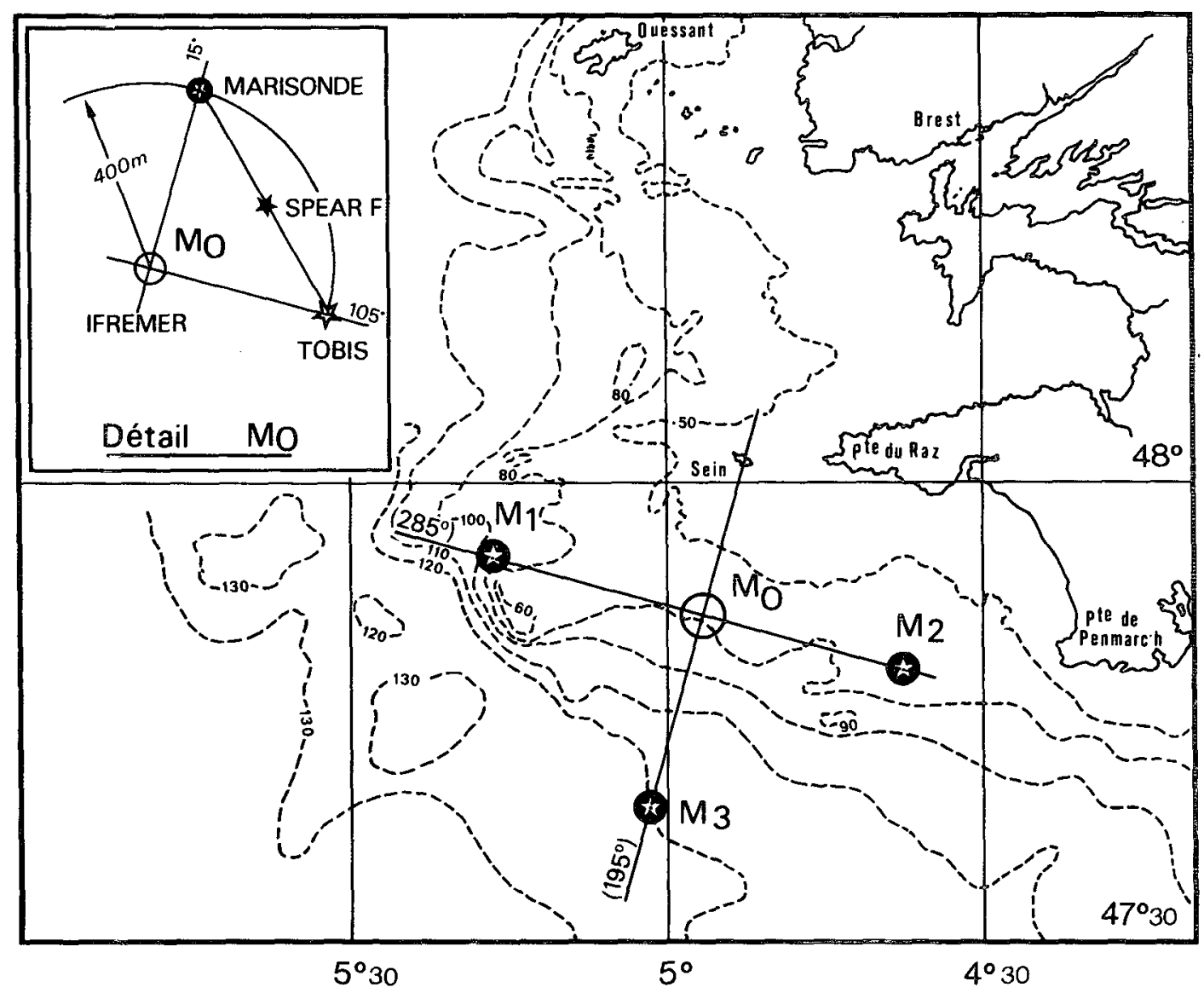

FIG. 1. TOSCANE-2 experimental area and moorings. 


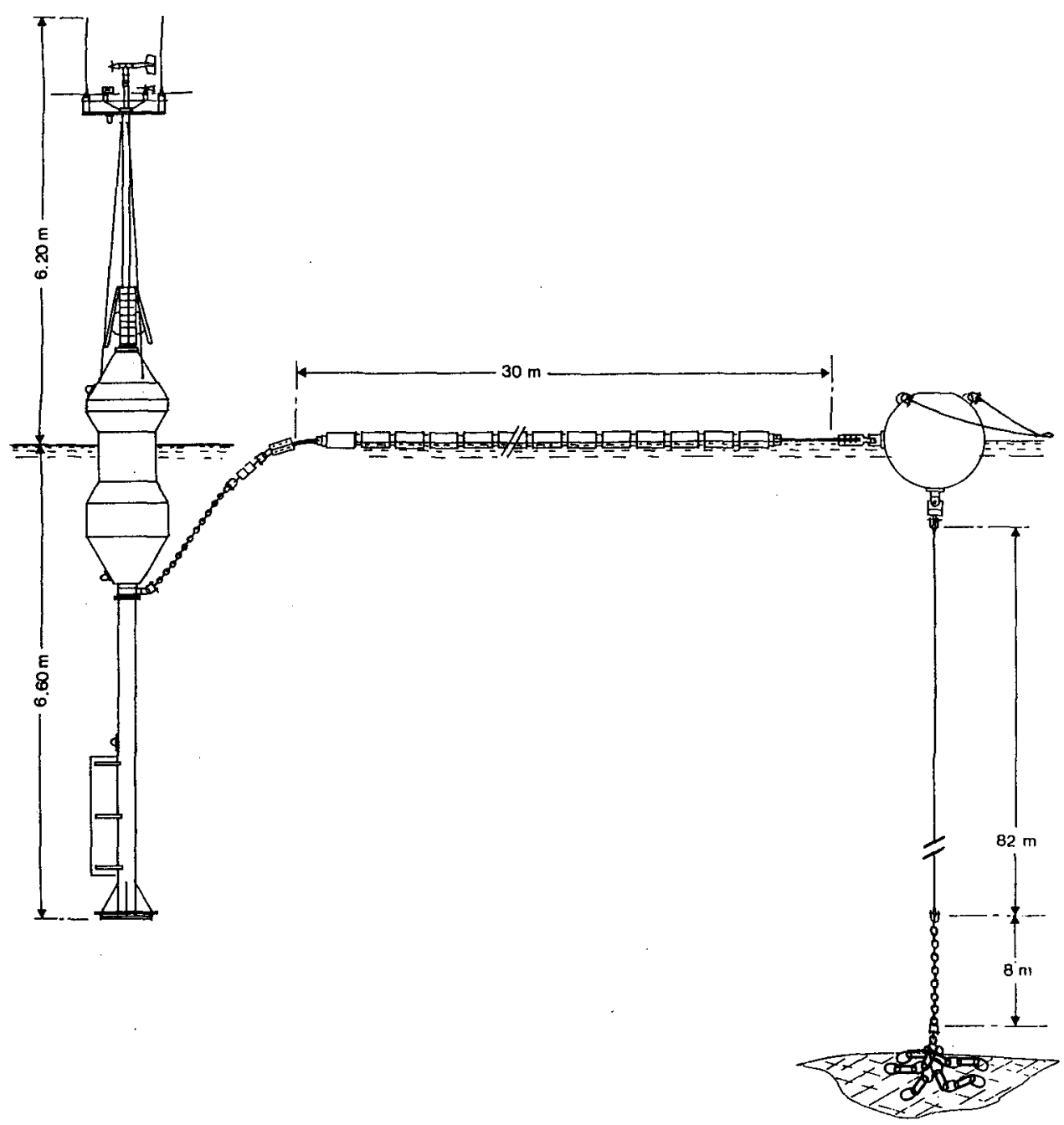

FIG. 2. The IFREMER prototype buoy and its mooring.

arctan being a four-quadrant function equal to the standard $\tan ^{-1}$ if $C e$ is greater than 0 , and equal to 180 $+\tan ^{-1}$ otherwise. The $A$ and $B$ coefficients relating linearly the speed and the frequency output $\left[V\left(\mathrm{~m} \mathrm{~s}^{-1}\right)\right.$ $=A F(\mathrm{~Hz})+B]$ were obtained from calibration tests in a wind tunnel facility in Institut de Mecanique Statistique de la Turbulence (Marseille, France). Values of the coefficients are reported in Table 1, together with other buoy characteristics.

\section{2) BUOY 6 AND BUOY 7}

These two buoys were built on the Marisonde hull of CMM (Fig. 4), $7 \mathrm{~m}$ long ( $3 \mathrm{~m}$ above the sea surface) with a maximum diameter of $1.6 \mathrm{~m}$. A three-cup Debucourt anemometer and vane, fluxgate compass, navigation light, and radio transmitter were installed at the top of the mast. The acquisition unit was a Cactus, identical to those of buoy 5 .

\section{3) CMM BUOY}

The CMM Marisonde buoy, in M0, was equipped with the three-cup Debucourt anemometer and vane, a Digicourse magnetic compass, and a CEIS electronic package, using the Argos satellite system for data transmission. It was a modified version of the Marisonde RC described in Daniault et al. (1988): the wind vector was averaged over $10 \mathrm{~min}$ and available every $15 \mathrm{~min}$, the data retrieval depending on Argos satellite passes and on the ship receiver location relative to the buoy (during the intensive part of the experiment). The buoy also measured, every $15 \mathrm{~min}$, the sea surface and air temperatures, the atmospheric pressure, and pressure tendency.

\section{4) SEIN ISLAND STATION}

On Sein Island, wind measurements were performed from a 10-m mast deployed at the extreme west of the 

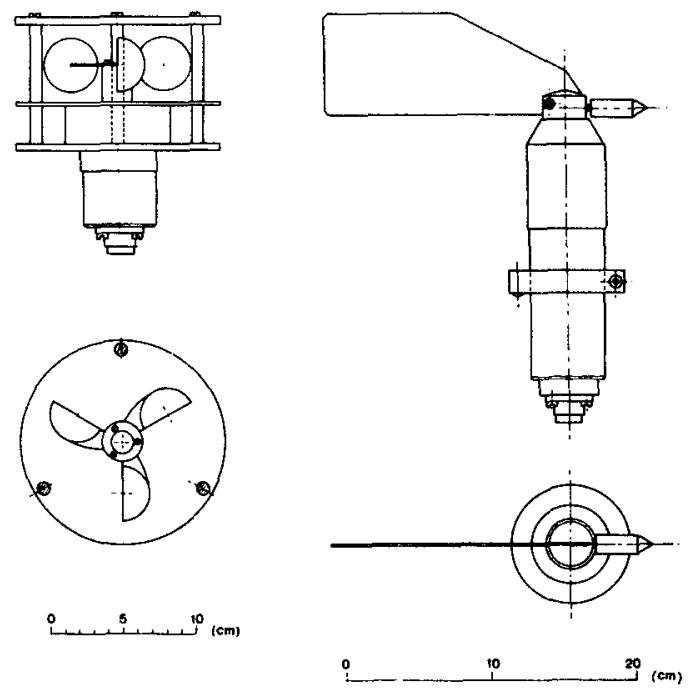

FIG. 3. Debucourt three-cup anemometer and vane.

island and equipped with Debucourt sensors and a Cactus unit. The mast was well exposed to winds blowing from directions outside of the range $30^{\circ}-140^{\circ}$. The height of the anemometer above mean sea level was about $16 \mathrm{~m}$.

\section{5) WAVE BUOY}

The Spear-f buoy, moored at location M0, is a modified Waverider from Datawell. A microprocessor computes, on board, the nondirectional sea-state spectrum and transmits the results via an Argos link, every hour. The duration of measurement is $34 \mathrm{~min} 8 \mathrm{~s}$. Details on this buoy are given in Ezraty et al. (1987).

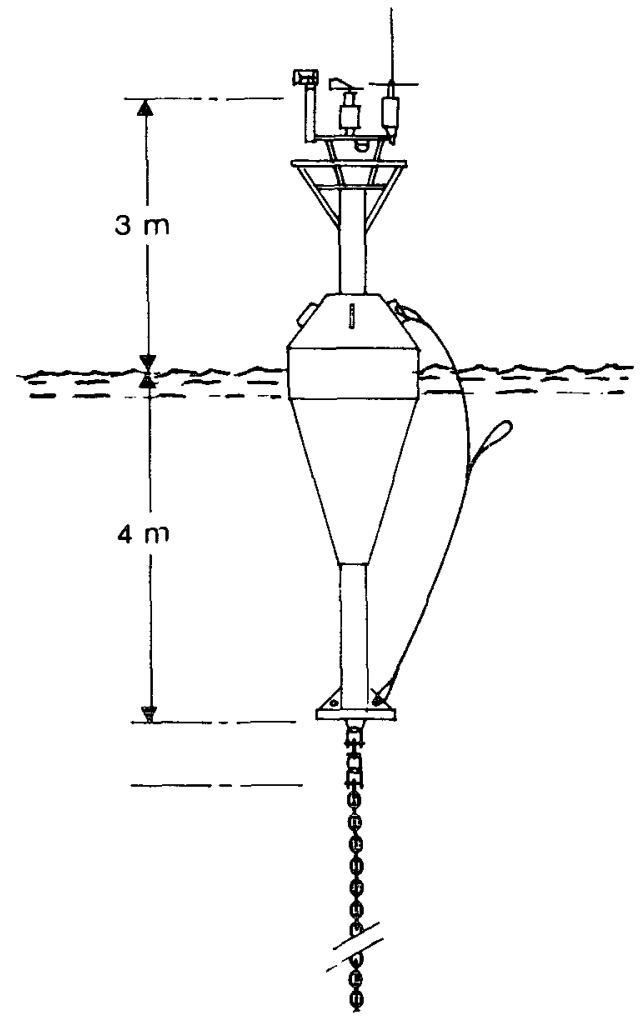

FIG. 4. The CMM Marisonde buoy hull.

\section{b. Ship measurement and operations}

The research vessel N/O Le Noroit was instrumented with two independent wind measurement systems. One was similar to those of buoys 5, 6, and 7 (Cactus and Debucourt three-cup anemometer and vane). The sec-

TABLE 1. Characteristics of buoys and wind measurement systems. Variables $A$ and $B$ are the anemometer calibration coefficients and $H$ is the height of the anemometer above the sea surface.

\begin{tabular}{|c|c|c|c|c|c|c|c|}
\hline Buoy or support & $\begin{array}{c}\text { Position } \\
\text { lat }\left({ }^{\circ} \mathrm{N}\right) \\
\text { long }\left({ }^{\circ} \mathrm{W}\right)\end{array}$ & $\begin{array}{l}\text { Depth } \\
\text { chart } \\
\text { (m) }\end{array}$ & $A^{\mathrm{Ar}}$ & $\stackrel{\text { neter }}{{ }_{B}}$ & $H(\mathrm{~m})$ & $\begin{array}{l}\text { Averaging } \\
\text { time }\end{array}$ & $\begin{array}{l}\text { Sampling } \\
\text { rate }\end{array}$ \\
\hline $5\left(M_{0}\right)$ & $\begin{array}{c}47^{\circ} 51^{\prime} 53^{\prime \prime} \\
4^{\circ} 56^{\prime} 30^{\prime \prime}\end{array}$ & 65 & 0.401 & -0.315 & 5.0 & $1 \mathrm{~min} / 2 \mathrm{~min} 30 \mathrm{~s}^{*}$ & continuous \\
\hline $6\left(M_{3}\right)$ & $\begin{array}{c}47^{\circ} 38^{\prime} 37^{\prime \prime} \\
5^{\circ} 01^{\prime} 43^{\prime \prime}\end{array}$ & 121 & 0.328 & 0.407 & 3.4 & & continuous \\
\hline $7\left(M_{1}\right)$ & $\begin{array}{c}47^{\circ} 55^{\prime} 15^{\prime \prime} \\
5^{\circ} 15^{\prime} 54^{\prime \prime}\end{array}$ & 80 & 0.358 & 0.236 & 4.0 & $1 \mathrm{~min} / 2 \mathrm{~min} 30 \mathrm{~s}$ & continuous \\
\hline Le Noroit & & & $\begin{array}{l}0.328 \\
0.10\end{array}$ & $\begin{array}{l}0.104 \\
0.0\end{array}$ & $\begin{array}{l}18 \\
18\end{array}$ & $30 \mathrm{~s}$ & continuous \\
\hline Sein Island & $\begin{array}{r}48^{\circ} 02^{\prime} 29^{\prime \prime} \\
4^{\circ} 52^{\prime} 09^{\prime \prime}\end{array}$ & . & 0.339 & 0.015 & 16 & $1 \mathrm{~min} / 2 \mathrm{~min} 30 \mathrm{~s}$ & continuous \\
\hline $\operatorname{CMM}\left(M_{0}\right)$ & $\begin{array}{c}47^{\circ} 52^{\prime} 05^{\prime \prime} \\
4^{\circ} 56^{\prime} 24^{\prime \prime}\end{array}$ & 65 & 0.343 & 0.0 & 2.7 & $10 \mathrm{~min}$ & $15 \min ^{*}$ \\
\hline
\end{tabular}

*: change $1 \mathrm{~min} / 2 \mathrm{~min} 30 \mathrm{~s}$ on day 340

**: rate of data retrieval depends on Argos satellite passes and on ship dedicated receiver location relative to the buoy 


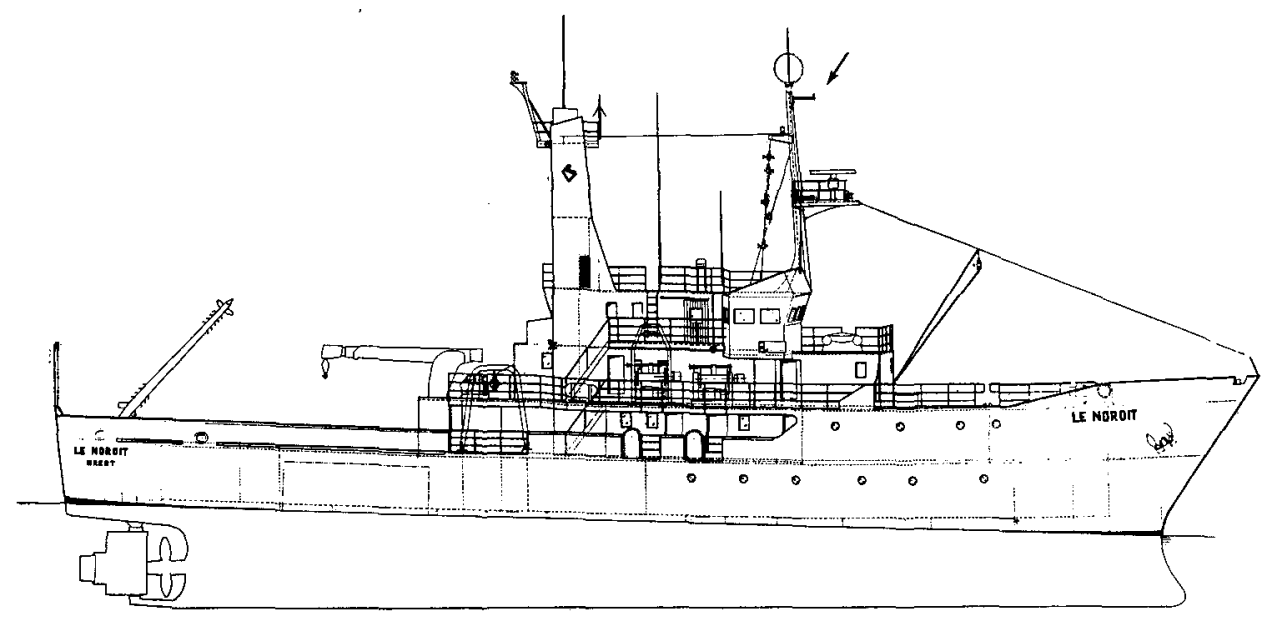

FIG. 5. N/O Le Noroit ( $50 \mathrm{~m}$ length); the arrow indicates the location of anemometers.

ond one was a ship meteorological station (Pomar) using a Tavid three-cup anemometer and vane. Both pairs of sensors were installed, $18 \mathrm{~m}$ above sea level, above the main bridge on the forward mast of the ship. The anemometers were set $0.65 \mathrm{~m}$ to port and starboard of the mast and $0.70 \mathrm{~m}$ forward of it (Fig. 5). Dryand wet-bulb air temperatures, atmospheric pressure, sea surface temperature, wave directions, ship heading, speed, and position were recorded. Sampling rates and averaging times are given in Table 2 . During the intensive part of the campaign N/O Le Noroit achieved the following tasks: buoy data recovery through VHF radio link and first check of data consistency; survey of the network, consisting of changing and repairing buoy sensors or electronics when damaged; and calibration of buoy wind measurements through dedicated runs.

\section{c. Data}

A summary of the network data return is given in Fig. 6. The mooring of buoys was achieved on 5, 6, and 7 November by the service vessel George De Joly operated by STPB (Service Technique des Phares et Balises). The N/O Le Noroit was in operation over the experiment area from 19 November until 6 December. The Sein Island data cover 130 days, from 5 November to 4 March with only two gaps: from $27-$ 29 November, during which the wind direction is not available (vane incident), and during $5 \mathrm{~min}$ on $6 \mathrm{De}-$ cember. The wave Spear-f buoy had a $100 \%$ data return and measurements are available over 73 days, from 7 November to 19 January.

Time series plots of Figs. 7 and 8 show the 30 -minaveraged wind speed and direction (from which the wind is blowing) from Sein Island measurements, the atmospheric surface pressure, the sea surface temperature (SST), the difference between air and SST firom CMM buoy data at location M0, and the significant wave height from Spear-f buoy data. Meteorological conditions during TOSCANE- 2 were governed by the relative locations and evolutions of low pressure systems over the northeast Atlantic Ocean and high pressure systems of Azores or over Europe. The atmospheric surface-pressure curves of Figs. 6 and 7 show the succession of lows and highs. The seasonal decrease

TABLE 2. Parameters measured on board N/O Le Noroit.

\begin{tabular}{llcc}
\hline \multicolumn{1}{c}{ Parameter } & Device & Acquisition sampling rate & Record-averaging time \\
\hline Wind 1 & Cactus & $\begin{array}{c}\text { Averaged wind vector } \\
\text { over 3 s }\end{array}$ \\
$\begin{array}{llc}\text { Wind 2 } \\
\text { Temperatures: } \\
\text { dry-, wet-bulb air, }\end{array}$ & Pomar & $0.5 \mathrm{~s}$ & $30 \mathrm{~s}$ \\
$\quad$ and sea surface & Probes & $0.5 \mathrm{~s}$ & $30 \mathrm{~s}$ \\
Bucket temperature & & $1 \mathrm{~h}$ & no averaging \\
Pressure & Altimeter & $1 \mathrm{~h}$ & no averaging \\
Wave direction & Radar/eyes & $1 \mathrm{~h}$ & no averaging \\
Ship heading & Gyrocompass & $3 \mathrm{~s}$ & no averaging \\
Ship speed & Loch & $3 \mathrm{~s}$ & no averaging \\
Ship position & SYLEDIS & $30 \mathrm{~s}$ & noveraging \\
\hline
\end{tabular}



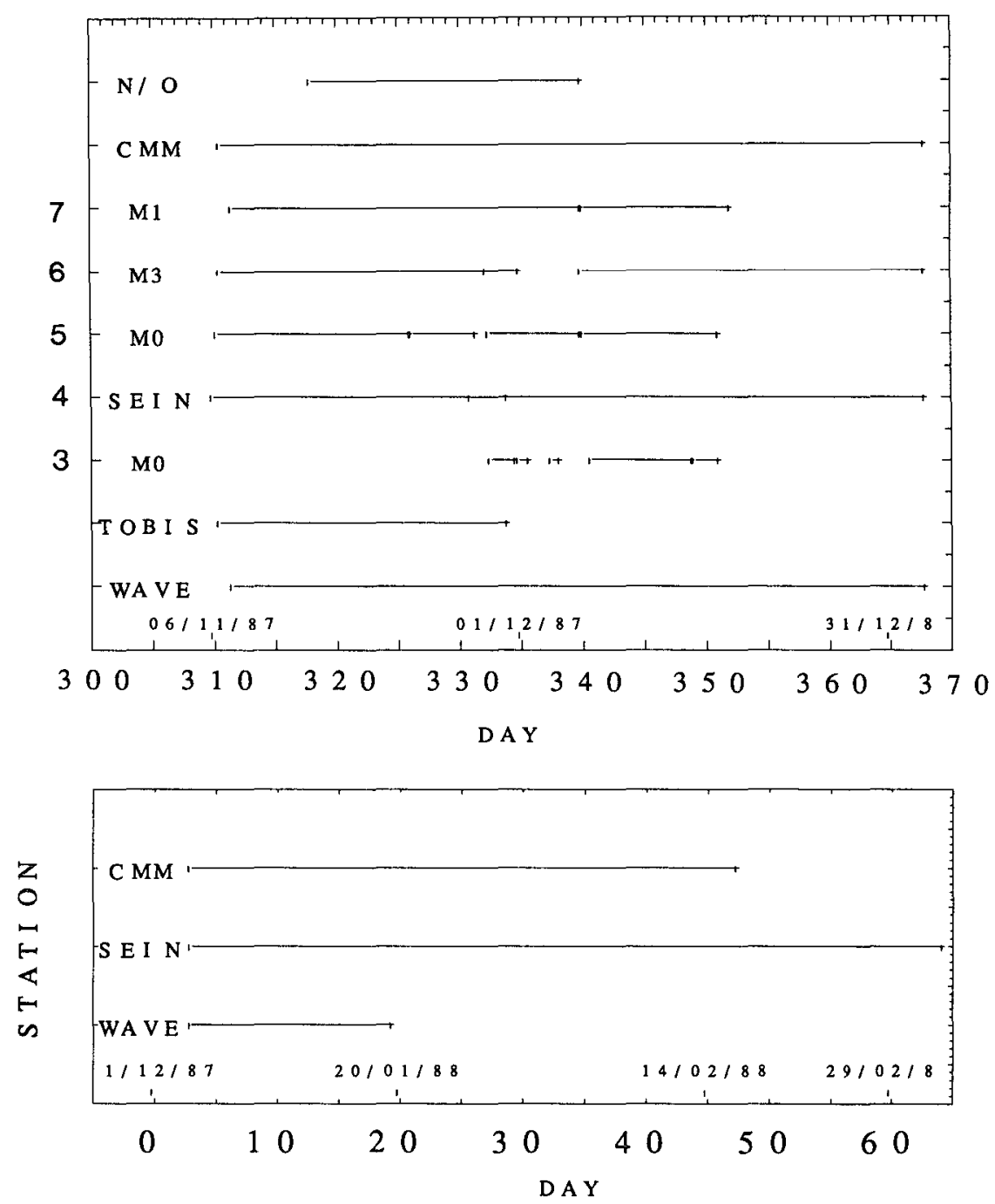

FIG. 6. TOSCANE-2 experiment data return.

of the SST is observed, from $14^{\circ} \mathrm{C}$ on day 310 to $10.5^{\circ} \mathrm{C}$ on day 47 of 1988 . Some modulation appeared from time to time (day 345 to 350 , for instance), due to tidal current (M. Tremant, CMM, personal communication). The air temperature was generally less than or equal to the SST, from day 310 to 348 , with an exception on day 339. Between days 349 and 365 , two periods of stable conditions occurred. After this date the conditions were unstable or near neutral. Wave height is roughly correlated to the wind speed for onshore wind, days 3-4 and 316-317, for instance, but not for easterly wind (days 335-350) for which the sea state is lower, in spite of high wind speed, because of limited fetch.

\section{Wind measurement errors and corrections}

Calibration of anemometers in a wind tunnel facility leads to linear relations between the frequency output of the sensors and the speed of the steady airflow, for speed above a few tens of centimeters per second. But the sensor responses differ significantly at sea, mainly because of the turbulent wind fluctuations and the wave-induced motions of buoy or ship. Furthermore, when wind measurements are performed on a ship, the data have to be corrected for the airflow distortion induced by the ship superstructures, for the speed of the ship, and for the altitude of the sensors above sea level. This is discussed in this section, together with particular characteristics of the Debucourt and Young anemometers.

\section{a. Sensor response at sea}

Three-cup anemometers generally overestimate the wind speed (values between $10 \%$ and $20 \%$ were reported in the literature), and propeller anemometers underestimate. A broad review of the subject is avail- 

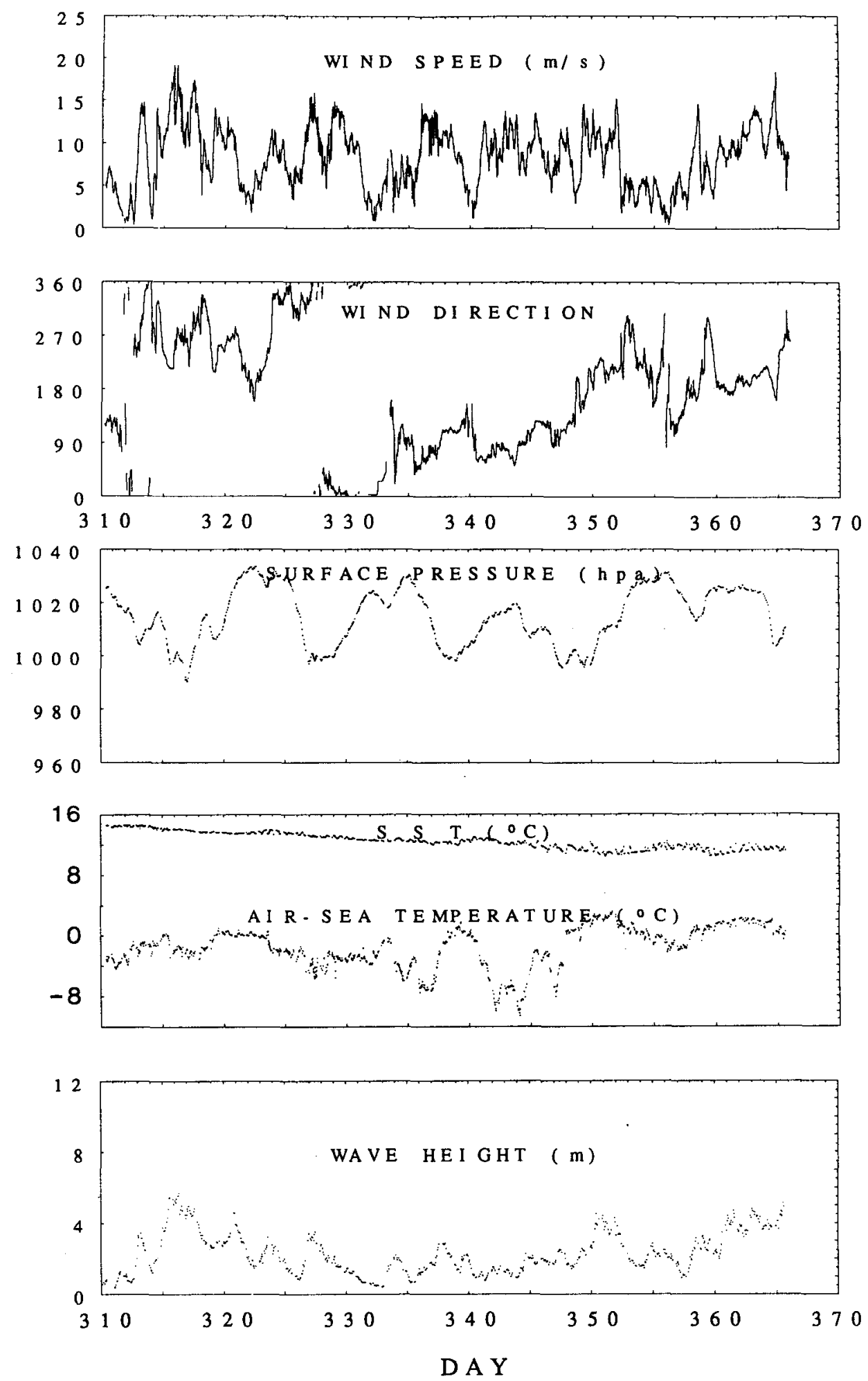

FIG. 7. Meteorological conditions experienced during the TOSCANE-2 campaign from day 310 to day 365 of 1987: wind speed and direction (mast on Sein Island), atmospheric surface pressure, sea surface temperature, difference between air and sea temperatures, and significant wave height. 

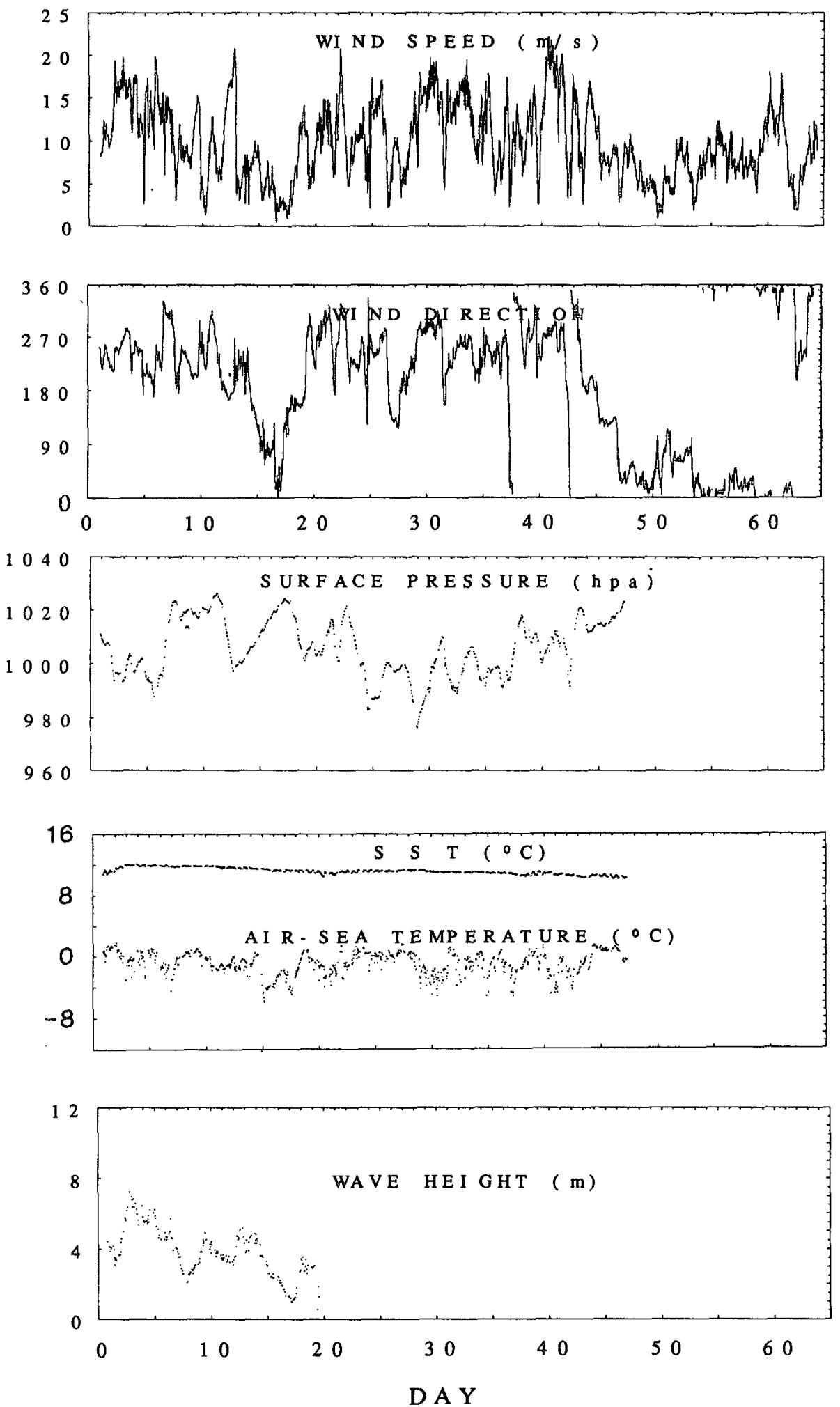

FIG. 8. Same as Fig. 7 for day 1 to day 65 of 1988. 
able in Weller et al. (1983). The authors identified two particular sources of error for rotating anemometers, even when accurately calibrated in steady flow: "the inability of the sensors to follow high-frequency fluctuations in the wind vector," and "a lack of cosine angular response functions in either the horizontal or vertical." Cup anemometers are known to respond more quickly to rapid increases in wind speed than to rapid decreases, which results, on average, in a measured speed higher than the real one. Furthermore, this overspeeding effect may change from one anemometer to another according to the mechanical friction. The vertical response functions increase this difference between the two types of sensors: the responses are generally above the cosine curve for cup anemometers (resulting in overestimation of measured values) and below for propellers (underestimation). After the experiment, the off-axis response of the R. M. Young propeller was tested in a wind tunnel (Maresca and Favier 1988). The experimental dataset shows that the underestimation of speed is symmetrical relative to the off-axis angle and that it increases with wind speed: for angles below $15^{\circ}$ the attenuation is less than $5 \%$ and for a $20^{\circ}$ incidence angle the attenuation is $5 \%$ at 5 $\mathrm{m} \mathrm{s}^{-1}, 10 \%$ at $10 \mathrm{~m} \mathrm{~s}^{-1}$, and $14 \%$ at $15 \mathrm{~m} \mathrm{~s}^{-1}$. For the extreme angle of $30^{\circ}$, it reaches $18 \%, 19 \%$, and $21 \%$, respectively. A performance analysis of the Frontal AirSea Interaction Experiment (FASINEX) meteorological buoys, performed by Weller et al. (1990), led to similar results from comparison of a three-cup anemometer and a Young propeller mounted on a similar buoy: an average $10 \%$ overestimation of the cup, with a strong correlation between overspeeding and atmospheric instability because of gusts. Therefore, the accuracy of the measurement is influenced by the geometry of the buoy hull and its response to sea waves. A spar buoy is more stable, and W. V. Burt (1975) reported an overestimation of $7 \%$ of wind speed measurements from a toroid buoy relative to a spar buoy equipped with the same type of three-cup anemometer.

A second effect of waves on a buoy is movement of the anemometer back and forth. For three-cup anemometers, the induced error will be large if wind speed and direction are averaged independently, particularly for light wind and swell conditions. If a quasi-sinusoidal motion is assumed, this error will be reduced in performing wind vector averaging at a high sampling rate (relative to wave periods). This was achieved by the acquisition system used on buoys and the ship (section 2).

In the case of the Debucourt anemometer, another error is due to the crossbars used to maintain the upper horizontal protecting disk (see Fig. 3). Postexperiment tests in a wind tunnel facility (Maresca and Favier 1988) have shown the influence of the bars: Fig. 9 presents the anemometer-sensed wind speed as a function of the horizontal azimuth for a nominal speed of 10 $\mathrm{m} \mathrm{s}^{-1}$ in the tunnel. The zero origin of the azimuth is centered on one of the three bars, and three minima

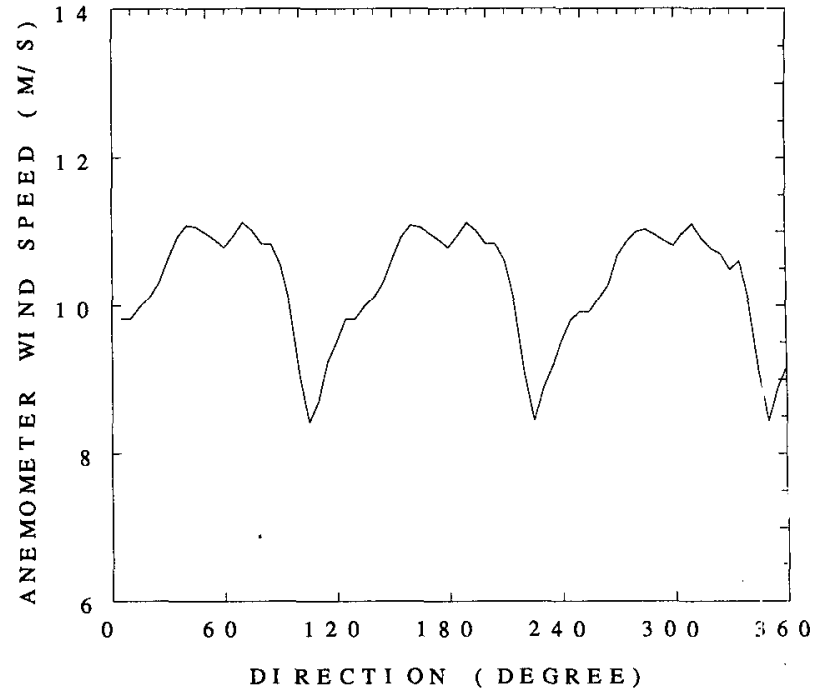

FIG. 9. Variation of the Debucourt anemometer-measured wind speed as a function of wind azimuth, for $10 \mathrm{~m} \mathrm{~s}^{-1}$ nominal wind speed, from tunnel experiment.

are observed, corresponding to each of the bars (the minina are in fact shifted about $10^{\circ}$ relative to the bars). The difference between maximum and minimum values is $2.5 \mathrm{~m} \mathrm{~s}^{-1}$ for a $10 \mathrm{~m} \mathrm{~s}^{-1}$ nominal speed, but the width of the minimum being narrow, differences for in situ measurements would be smoother than those observed in the tunnel. Comparison of the wind speed data from the island mast (Debucourt anemometer) and the buoy 5 (Young anemometer, without crossbars) as a function of mast wind direction (Fig. 10) shows clearly the same shape (with a level change from west to east sectors). This is also observed for buoys 6 and 7, though equipped with the same type of crossbars: the perturbation effect of crossbars is smoothed because of the buoy motion. This large perturbation is certainly the main explanation for the modulation observed by Daniault et al. (1988) on wind speed differences between masts as a function of vind direction, during the TOSCANE-T experiment (their Fig. 8).

\section{b. Ship airflow distortion}

Wind speed and direction measurements on a ship can be seriously perturbed by the airflow distortion induced by superstructures, resulting in an acceleration of the flow above and around the ship. Induced errors are very sensitive to the location of the sensors and to the direction of the wind relative to the ship. From simulations in a wind tunnel on a 1:100-scale ship model (Blanc 1986), these errors were estimated and correction tables proposed for two standard anemometer locations on both sides of the forward mast. For wind speed measurements, the minimum error was observed near the upwind direction and estimated at $12 \%$ and $10 \%$ for starboard and port anemometer, re- 


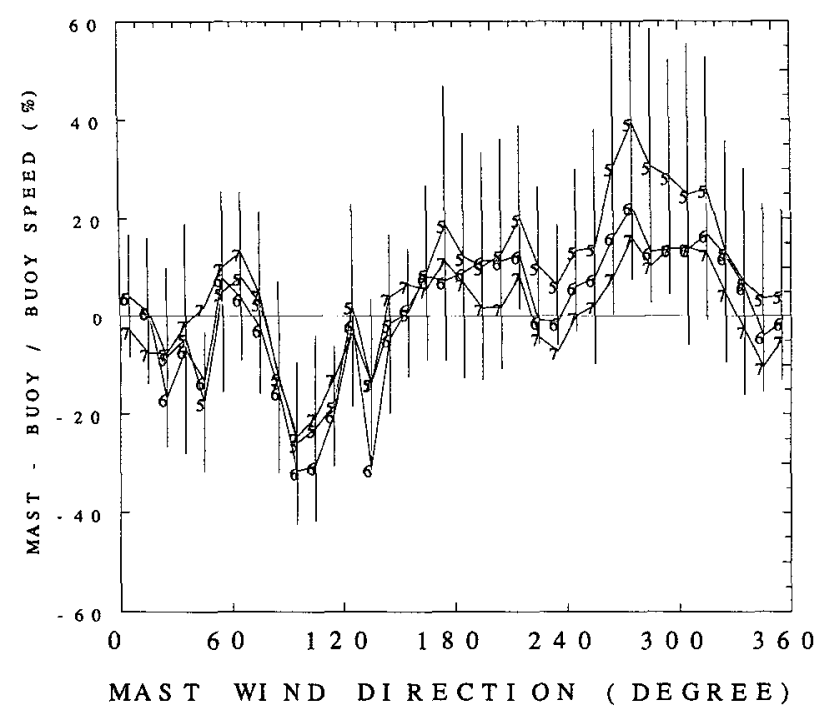

FIG. 10. Relative (to buoy) differences between mast and buoy wind speeds as a function of mast wind direction: 20-min-averaged data corrected to the mast altitude measurement and grouped within direction bins $10^{\circ}$ wide, for buoys 5,6 , and 7 . Vertical bars for buoy 5 indicate plus/minus one standard deviation computed within each direction class.

spectively. When the relative wind direction changes within $\pm 30^{\circ}$, the error ranges from $18 \%$ to $8 \%$ on starboard and from $11 \%$ to $13 \%$ on port, reflecting the asymmetrical configuration of the ship. For direction, errors are between $-7^{\circ}$ and $1^{\circ}$ on starboard and between $0^{\circ}$ and $6^{\circ}$ on port, the minimum being slightly outside the upwind direction. These results were obtained in the assumption of neutral stability conditions and the author estimated the accuracy of the corrected values under other environmental conditions to be of the order of $\pm 5 \%$ for speed and $\pm 5^{\circ}$ for direction. Other overspeeding values between $10 \%$ and $20 \%$ are reported by Blanc (1985) and Kahma and Lepparanta (1981).

This effect was roughly estimated during the TOSCANE-1-PROMESS campaign (Ezraty and Queffeulou 1987), on board N/O Le Suroit, from dedicated experiments consisting of measuring the relative wind speed during two following runs, the ship heading upwind in the first and downwind in the second, at a speed which must be greater than the wind speed (about $10 \mathrm{kt}$ maximum). The ship speed relative to the bottom was computed from the positioning system data, and with the assumption that wind speed was steady over the two following runs, the overspeeding induced by the ship airflow distortion was estimated at about $8 \%$ of the measured speed. The reference quoted above gives a value of $12 \%$, which includes a $4 \%$ difference due to anemometer calibration. This overspeeding value is less than those reported above, but the error on this estimation might be large because the assumption of constant wind speed, on average, over the two following runs (each about $20 \mathrm{~min}$ long) might not be verified. Nevertheless, this correction will be applied to the data, but its questionable accuracy has to be kept in mind.

\section{c. Correction for ship speed}

Once the overspeeding correction is achieved, the relative wind speed is corrected for the ship speed, deduced from the SYLEDIS (Système Léger de mesure de Distance) data, at a 30-s sample rate. The SYLEDIS is a radio hyperbolic positioning system based on local transmitters of the Marine Nationale, and the position accuracy is better than $10 \mathrm{~m}$ over the experimental area. So, when vector averaging is performed over time duration longer than $10 \mathrm{~min}$, the resulting speed accuracy is better than $0.03 \mathrm{~m} \mathrm{~s}^{-1}$ and the correction does not contribute significantly to the variance observed when comparing ship and buoy data.

\section{d. Adjustment of wind to a reference level}

In the following sections, ship, buoy, and mast data will be compared and for this purpose wind speed data have to be corrected for height shifts relative to the sea level. This is achieved through a stability-dependent model in the constant flux layer. The wind speed at $z$ level is given by (1), $u_{*}$ being the friction velocity, $k$ $=0.4$ the von Kármán constant, and $z_{0}$ the aerodynamic roughness length. The aerodynamic roughness length $z_{0}$ is related to the friction velocity ( $\mathrm{Wu} 1982$ ) by $(2), \mu=14.10^{-6} \mathrm{~m} \mathrm{~s}^{-1}$ being the kinematic viscosity of air and $g=9.81 \mathrm{~m} \mathrm{~s}^{-2}$ the gravity acceleration:

$$
\begin{gathered}
u(z)=\left(\frac{u_{*}}{k}\right)\left[\ln \left(\frac{z}{z_{0}}\right)-\psi_{m}\left(\frac{z}{L}\right)\right] \\
z_{0}=\frac{0.0185 u_{*}^{2}}{g}+\left(\frac{\mu}{u_{*}}\right) \exp (-5.5 k) .
\end{gathered}
$$

The parameter $\psi_{m}$ is a stability-dependent function (Large and Pond 1981) equal to 0 for neutral conditions and given by (3) and (4) for stable and unstable conditions, respectively. The Monin-Obukhov stability length, estimated through the bulk formulas parameterization of turbulent fluxes is represented by $L$. The value of $u(z)$ is computed through an iterative method, using the software package developed by Ezraty and Ollitrault (1985). Thus,

$$
\begin{gathered}
\Downarrow_{m}\left(\frac{z}{L}\right)=\frac{-5 z}{L} \\
\psi_{m}\left(\frac{z}{L}\right)=2 \ln \left[\frac{(1+X)}{2}\right]+\ln \left[\frac{\left(1+X^{2}\right)}{2}\right] \\
-2 \tan ^{-1} X+\frac{\pi}{2}
\end{gathered}
$$

with $X=(1-16 z / L)^{1 / 4}$. 


\section{Consistency of ship wind measurements}

Data from the two independent wind measurement systems on board the ship were compared. The comparison was performed on relative wind data (as measured by the two wind systems and not corrected for ship speed and distortion). This information is directly available from the Cactus station (30-s average) using the Debucourt sensors and an internal compass. For the Pomar station (Tavid sensors) a wind vector is available at 3-s average; the direction of this wind vector refers to the ship axis and the transformation relative to north is performed using the ship gyrocompass data stored every $3 \mathrm{~s}$. These two datasets are then synchronized and averaged over $30 \mathrm{~s}$. Only data collected during calibration runs are compared, which represent 21606 data points. Calibration runs are defined within the three following criteria: the ship-to-buoy distance is restricted to a maximum value of two nautical miles; the ship is heading upwind (difference between ship heading and wind direction being less than $30^{\circ}$ ) so that the airflow distortion induced by the ship superstructure is always the same; and the ship speed is as low as possible but high enough to maintain upwind (i.e., less than $3 \mathrm{kt}$ ).

\section{a. Wind direction}

The mean value of the differences between the two datasets is $5.9^{\circ}$ and the standard deviation of the differences is $4.5^{\circ}$. The mean difference is small and compatible with possible asymmetrical deflection of wind direction as reported in section $3 \mathrm{~b}$. The distribution of the differences, shown in Fig. 11, is narrow: $47.9 \%$ of the data are within $\pm 5^{\circ}$, and $85.8 \%$ within $\pm 10^{\circ}$. When taking the mean value $m$ into account, the following

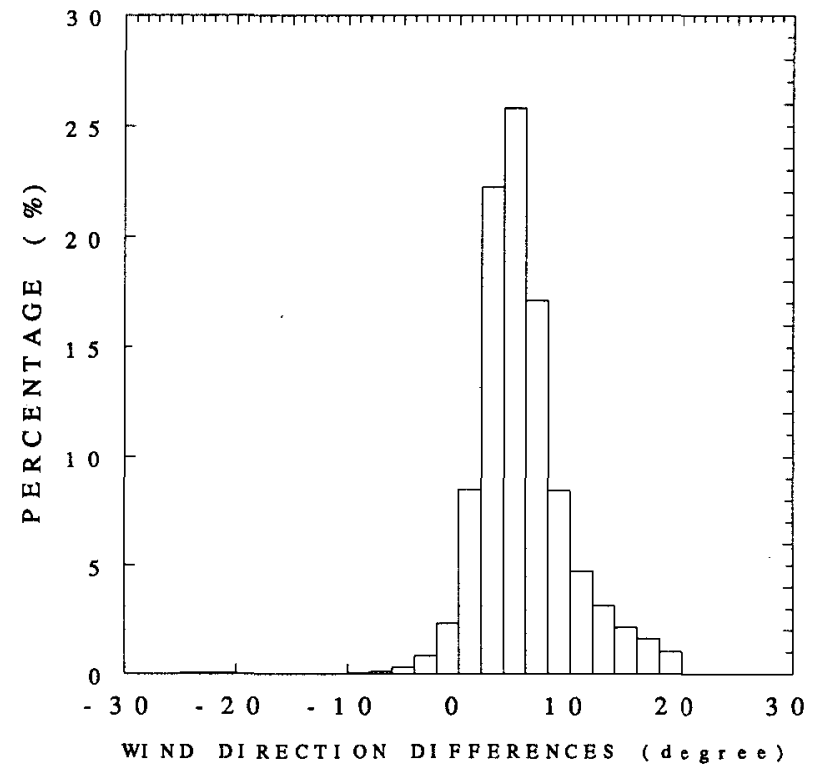

FIG. 11. Distribution of wind direction differences between the two measuring systems (Cactus and Pomar) on board N/O Le Noroit.

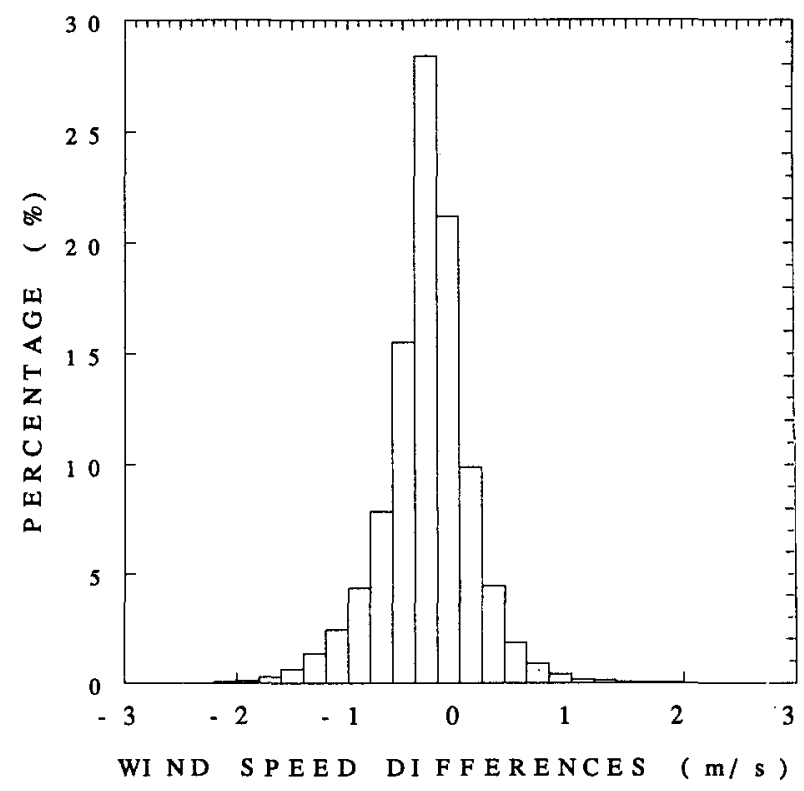

FIG. 12. Distribution of wind speed differences between the two measuring systems (Cactus and Pomar) on board N/O Le Norioit.

results are obtained: $82.1 \%$ within $m \pm 5^{\circ}$, and $95.3 \%$ within $m \pm 10^{\circ}$. These results are rather good, since the Tavid vane resolution is only $10^{\circ}$.

\section{b. Wind speed}

The distribution of the wind speed differences is shown in Fig. 12: the mean value is $-0.29 \mathrm{~m} \mathrm{~s}^{-1}$, Debucourt speed being lower, and standard deviation is $0.40 \mathrm{~m} \mathrm{~s}^{-1} ; 99.9 \%$ of data are within $\pm 2 \mathrm{~m} \mathrm{~s}^{-1}$ and $94.8 \%$ of data within $\pm 1 \mathrm{~m} \mathrm{~s}^{-1}$. After correcting for
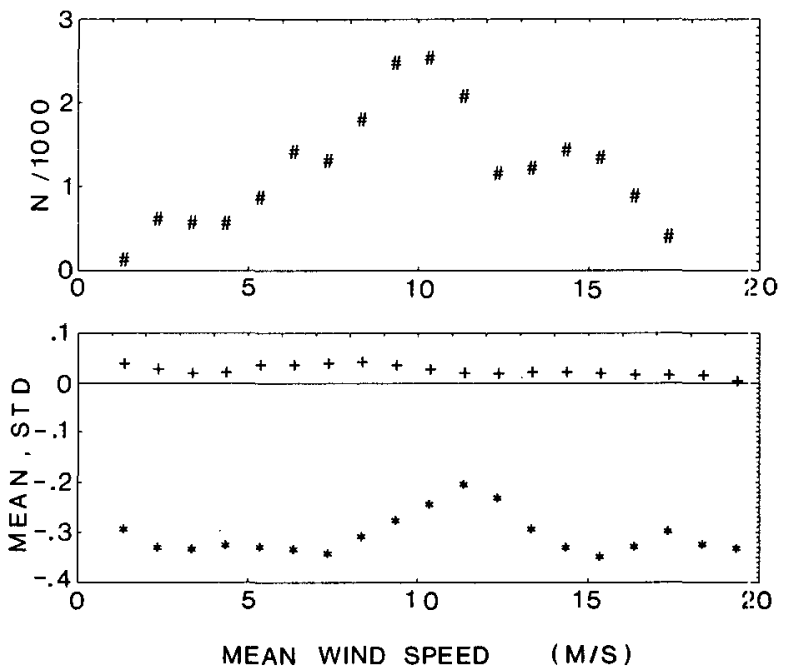

FIG. 13. Variation of mean value $\left(*, \mathrm{~m} \mathrm{~s}^{-1}\right)$ and standard deviation ( + , ratio to the speed) of speed differences between the two measuring systems (Cactus and Pomar) on board N/O Le Noroit as a function of the mean wind speed of the two systems. The upper curve (\#) is the number of data for each speed bin. 
the $-0.29 \mathrm{~m} \mathrm{~s}^{-1}$ bias, $97.2 \%$ of data are within \pm 1 $\mathrm{m} \mathrm{s}^{-1}$.

Figure 13 shows the evolution of the mean value and standard deviation of the speed differences as a function of the averaged wind speeds measured by Cactus and Pomar systems (bin width is $1 \mathrm{~m} \mathrm{~s}^{-1}$ ): the mean is roughly constant; the standard deviation increases with wind speed, from 0.10 to $0.49 \mathrm{~m} \mathrm{~s}^{-1}$, the ratio to the wind speed, shown on the figure, varying between 0.03 and 0.05 . When the mean value of the differences is taken into account, the analysis of the relative dispersion indicates that $94.3 \%$ of data are within $\pm 10 \%$ of Cactus wind speed.

These results show that the wind measurements performed on board the ship by the two systems are in close agreement. The dataset obtained from the Cactus system (equipped with the Debucourt sensors, as most of the buoys) will be considered as a reference, although the $0.3 \mathrm{~m} \mathrm{~s}^{-1}$ mean difference is not explained and the absolute accuracy is questionable (section $3 b$ ). It is important to note that these results are obtained over a narrow range $\left( \pm 30^{\circ}\right)$ of the wind azimuth relative to the anemometer (ship heading upwind), because in these conditions, the position of the Debucourt anemometer relative to the ship is such that no perturbation from the anemometer crossbars is expected.

\section{Comparison of buoy and ship wind data}

\section{a. Time-distance influence}

In order to compare buoy and ship wind measurements, the averaging time and the separation distance between the two platforms have to be chosen. An initial view of the time-distance influence is given in Fig. 14, showing the relative (to the ship) standard deviation of ship and buoy 5 wind speed differences according to averaging time and separation distance classes. The length of distance classes is not constant, but determined in order to obtain a constant number of data for each class $(400,200,150,60,45$, and 30 for the considered averaging times between 1 and $20 \mathrm{~min}$, respectively). First, the standard deviation decreases rapidly from 1 to 5 min averaging time; then, no significant difference is observed between 10 and $20 \mathrm{~min}$. So, in the following comparisons, the averaging duration will be set to $20 \mathrm{~min}$. The shape of the curves is not interpretable as a function of separation distance because wind speed distribution is not the same over all distance classes, and the standard deviation is certainly speed dependent. As the length of the dataset is limited and as the distance effect cannot be estimated, the whole dataset for which the distance is less than or equal to $3000 \mathrm{~m}$ will be taken into account hereafter. Increasing this value does not significantly change the number of data.

\section{b. Comparison of buoy and ship wind speed}

Assuming the ship measurements can be considered as a reference, the goal of these comparisons is to cal- ibrate measurements of buoys in order to get a homogeneous (as much as possible) wind dataset over the whole network.

The ship wind speed data have been reduced to the height of buoy sensors, using the boundary-layer model with, as input, the stability conditions inferred from ship measurements of atmospheric pressure, sea surface, and wet and dry air temperatures. Scatterplots of buoy and ship data are shown in Fig. 15. Each point corresponds to the value averaged over $20 \mathrm{~min}$, and vertical and horizontal bars represent plus or minus one standard deviation of the 1-min elementary data relative to the 20 -min-averaged value, for buoy (vertical) and ship (horizontal) data. This variability is shown in detail, in Fig. 16, for ship and buoy 6: the standard deviation is generally less for the ship than for the buoy but both variables increase with wind speed.

A straight line was fit to the dataset of Fig. 15 by minimizing the function $X^{2}(a, b)$ equal to the sum of the squares of the orthogonal distances $d_{i}$, between the data point $\left(x_{i}, y_{i}\right)$ and the line $y=a x+b$, weighted by the "variability" of the data point, $\sigma_{i}$ estimated as the square root of the sum of ship and buoy variances $\sigma_{x i}^{2}$ and $\sigma_{y i}^{2}$. Uncertainties on $a$ and $b$ are functions of those on $x_{i}$ and $y_{i}$, and standard deviations $\sigma_{a}$ and $\sigma_{b}$ have been estimated extending to two variables the propagation of errors used in Press et al. (1986).

Statistical results are summarized in Table 3. Mean values of differences between ship and buoy measurements range from -0.71 to $0.34 \mathrm{~m} \mathrm{~s}^{-1}$. The standard deviation of the differences are significantly different among the buoys: the minimum value is $0.29 \mathrm{~m} \mathrm{~s}^{-1}$

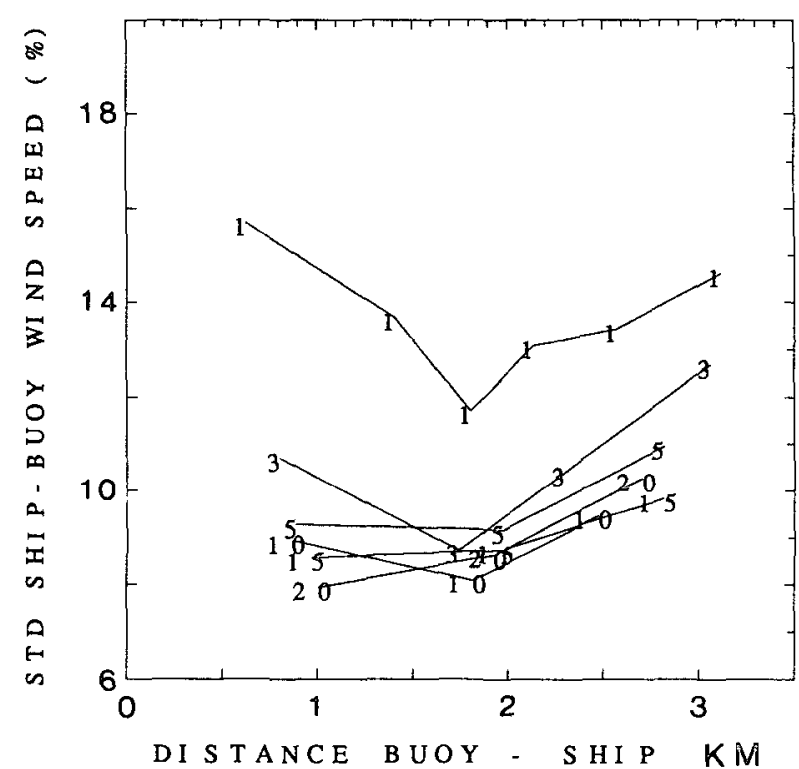

FIG. 14. Standard deviation of the relative (to the ship wind speed) differences between ship and buoy 5 wind speed as a function of separation distance, for $1,3,5,10,15$, and 20 min averaging time (curve label is averaging time). 

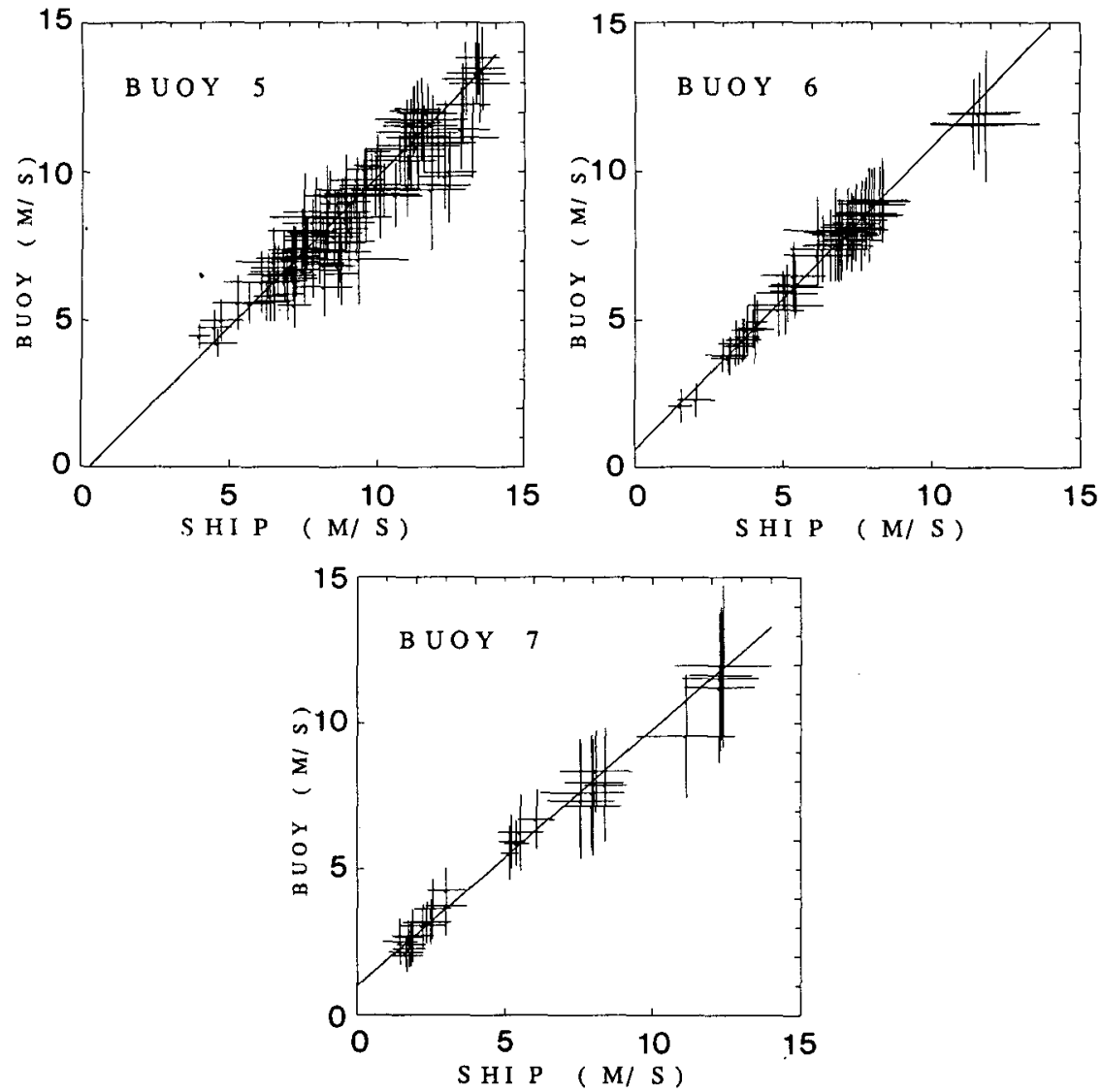

FIG. 15. Scatterplots comparing 20-min-averaged wind speeds from ship and buoys.
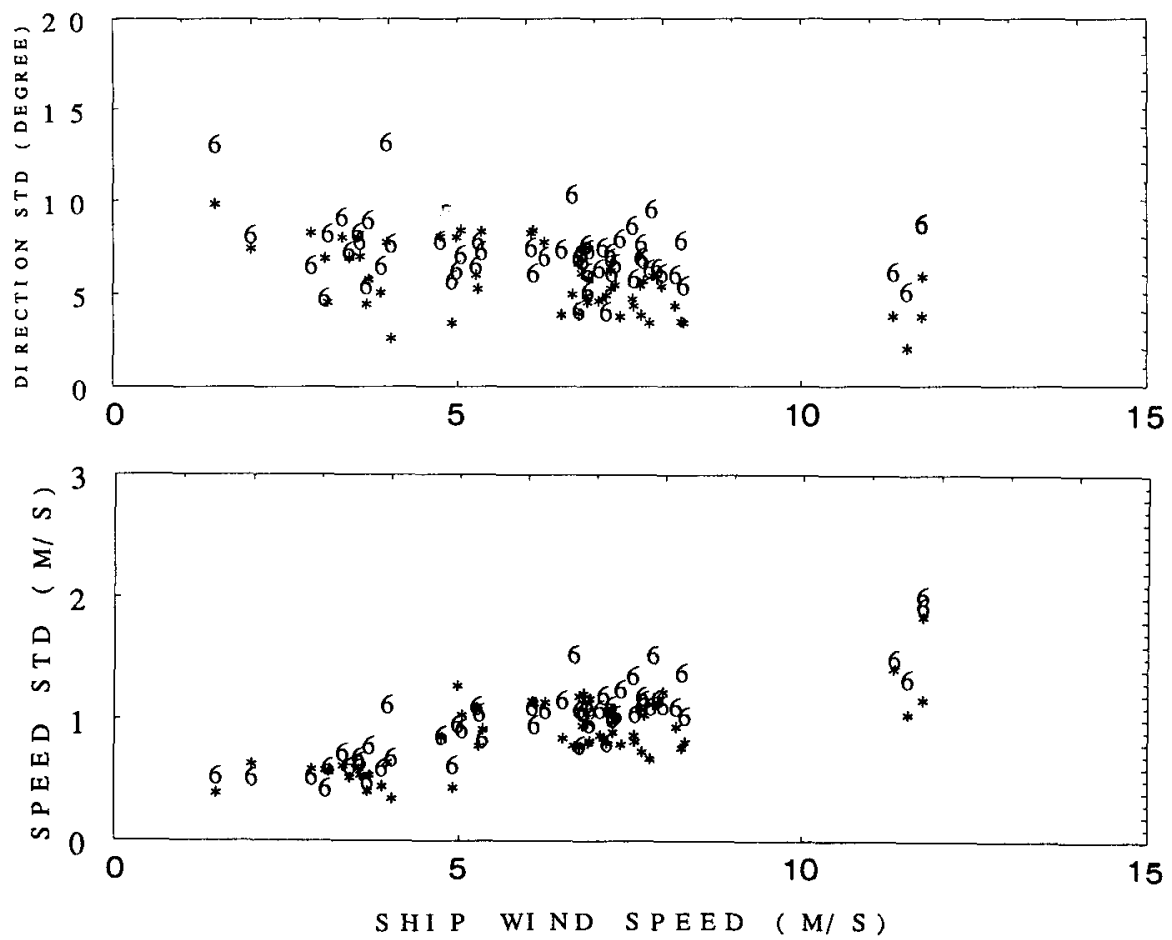

Fig. 16. Standard deviation of 1-min ship (*) and buoy 6 wind speed and direction measurements within $20 \mathrm{~min}$ averaging time. 
TABLE 3. Statistical results for ship and buoy wind speed comparisons $\left(\mathrm{m} \mathrm{s}^{-1}\right)$ : data point number $N$, mean value, and standard deviation of differences between ship and buoy data, slope $A$ and intercept $B$ of the inertial axis with their estimated standard deviation $\sigma_{A}$ and $\sigma_{B}$.

\begin{tabular}{lrrrrrrr}
\hline \hline Buoy & $N$ & Mean & $\begin{array}{l}\text { Standard } \\
\text { deviation }\end{array}$ & $A$ & $\sigma_{A}$ & $\sigma_{B}$ \\
\hline 5 & 119 & 0.34 & 0.82 & 1.012 & 0.053 & -0.269 & 0.46 \\
6 & 58 & -0.71 & 0.29 & 1.021 & 0.072 & 0.598 & 0.41 \\
7 & 30 & -0.22 & 0.71 & 0.879 & 0.083 & 0.993 & 0.35 \\
\hline
\end{tabular}

for buoy 6 and the maximum $0.82 \mathrm{~m} \mathrm{~s}^{-1}$ for buoy 5 . The slope of the regression lines is very close to unity for buoys 5 and 6 (about $1 \%$ and 2\%, respectively), but is $12 \%$ for buoy 7 . This buoy overestimates low wind speeds and underestimates high wind speeds $(>10$ $\mathrm{m} \mathrm{s}^{-1}$ ). Taking into account variances of ship and buoy measurements, the standard deviation of the slope coefficients is shown to range from $5 \%$ to $8 \%$, the maximum value being observed for buoy 7 . The values of the intercept range from -0.3 to $1.0 \mathrm{~m} \mathrm{~s}^{-1}$ (maximum for buoy 7) with standard deviation from 0.35 to 0.46 $\mathrm{m} \mathrm{s}^{-1}$.

The main conclusions from these results are that the wind speed measurement is biased, slightly low $(0.34$ $\left.\mathrm{m} \mathrm{s}^{-1}\right)$ for buoy 5 , and high $\left(0.71 \mathrm{~m} \mathrm{~s}^{-1}\right)$ for buoy 6 , which is in agreement with the three-cup overspeeding described in section 3. A large slope coefficient is observed for buoy 7 , which may indicate a miscalibration of the anemometer, though for this buoy the number of data is only 30 , which is statistically insufficient.

\section{c. Comparison of buoy and ship wind direction}

Statistical results comparing the directions of the 20 min-averaged wind from buoys and the ship are given in Table 4. Mean value of differences is less than $1^{\circ}$ for buoy 5 , only $-1.5^{\circ}$ for buoy 7 , and $5.5^{\circ}$ for buoy 6. Standard deviation is less than $5^{\circ}$ for buoys 5 and 6 and reaches $7.5^{\circ}$ for buoy 7 . The slopes are very close to unity and the intercepts are less than $5^{\circ}$. Standard deviations of the elementary $1-\mathrm{min}$ wind direction relative to the $20-\mathrm{min}$ average are given in Fig. 16 as a function of wind speed: as for the speed, the direction variability is less for the ship than for the buoys but it increases at low wind speed because of a higher variability of wind direction and a degraded response of vanes at light winds. In conclusion, results obtained for these direction comparisons may be considered very good.

\section{Buoy calibration and test}

Assuming the ship wind measurement is a reference, the regression coefficients $(a, b)$ obtained earlier will be used to calibrate the buoy data as $x_{c}=(x-b) / a$, $x$ being the buoy measurement (speed or direction) and $x_{c}$ the calibrated value. To test the efficiency of this calibration, the resulting wind data of the three buoys will be compared (values corrected to the height of $5 \mathrm{~m}$ in neutral stability conditions), but before this step, the buoys being separated by $25-35 \mathrm{~km}$, the averaging time has to be chosen long enough to filter out the effect of distance separation.

\section{a. Averaging-time effect}

The mean value and variance of the differences between calibrated wind directions from pairs of buoys were studied as a function of the averaging time, ranging from $10 \mathrm{~min}$ to $24 \mathrm{~h}$. When analyzing the whole dataset, large spikes were obtained on curves relating the mean and the standard deviation to the averaging time. Inspection of the data revealed that these spikes were mainly induced by three sequences, of duration of the order of $12 \mathrm{~h}$, for which directions measured by the two buoys are significantly different: discarding these time periods, the curves were smoother and the level of variance decreased. Two of the three perturbation sequences are illustrated in Fig. 17, showing 2.5-min-averaged wind speed and direction for buoys 5,6 , and 7 on days 345-349. The speed curves 6 and 7 have been shifted up by $8 \mathrm{~m} \mathrm{~s}^{-1}$ and $16 \mathrm{~m} \mathrm{~s}^{-1}$, and the direction curves by $30^{\circ}$ and $60^{\circ}$, respectively. A first anomaly is observed on day 345 when buoy 6 's speed and direction are significantly different from those of buoys 5 and 7 . The second perturbing sequence corresponds to a meteorological cold front propagating across the area at very low speed since the changes of wind direction are observed at 2140 UTC (day 347), 0110 UTC (day 348), and 0450 UTC on buoys 6,7 ,

TABLE 4. Ship and buoy wind direction comparisons (deg).

\begin{tabular}{rrrrrrrr}
\hline \hline Buoy & $N$ & Mean & $\begin{array}{c}\text { Standard } \\
\text { deviation }\end{array}$ & $A$ & $\sigma_{A}$ & $\sigma_{B}$ \\
\hline 5 & 119 & -0.38 & 3.66 & 0.984 & 0.005 & 2.890 & 0.77 \\
6 & 58 & 5.46 & 4.93 & 0.995 & 0.009 & -4.071 & 2.05 \\
7 & 30 & -1.50 & 7.35 & 1.000 & 0.037 & 0.966 & 2.87 \\
\hline
\end{tabular}



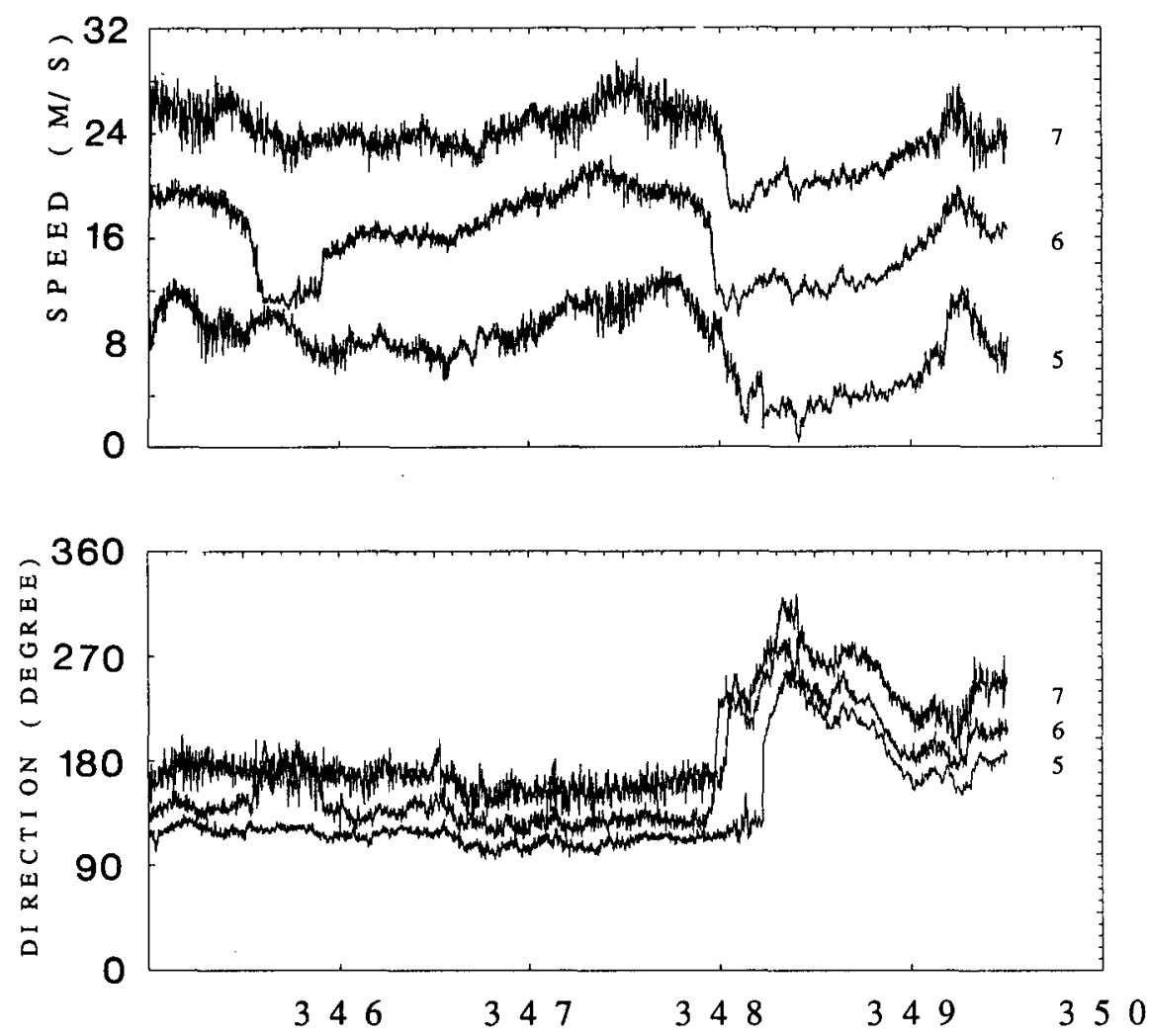

D A Y

FIG. 17. 2.5-min-averaged buoy wind data for days 345-349. Curves are shifted by $8 \mathrm{~m} \mathrm{~s}^{-1}$ steps for speed and by $30^{\circ}$ steps for direction.

and 5 , respectively. There is a time lag about $7 \mathrm{~h}$ long between changes of direction at buoys 5 and 6 , which are separated by $25 \mathrm{~km}$ only, and so when averaging, even over a duration as long as $12 \mathrm{~h}$, and comparing directions of buoys 5 and 6 , large differences may be observed depending on whether direction changes occurred on both buoys. The third perturbing sequence, not shown here, corresponds to low wind speed for which the direction is variable among buoys. In the following, these three sequences will be discarded, as also periods for which the speed is less than $1 \mathrm{~m} \mathrm{~s}^{-1}$.

Within these conditions, evolution of mean and variance of measurement differences between buoys 5 and 6 is shown in Figs. 18 and 19 for wind direction and speed. The standard errors reported on the graphs were estimated as $\sigma n^{-1 / 2}$ for the mean and $\left(m_{4}\right.$ $\left.-m_{2}{ }^{2}\right)^{1 / 2} n^{-1 / 2}$ for the variance, $m_{2}$ and $m_{4}$ being the second- and fourth-order central moments of the distribution. The curves obtained for the two remaining pairs of buoys, $(5,7)$ and $(6,7)$, have a similar shape. The variances decrease with averaging time, rapidly for the first 3 or $4 \mathrm{~h}$, then more slowly, and reach a plateau value around $10-12 \mathrm{~h}$. Some values of the standard deviation (absolute and relative to the 10min observed one) are given in Tables 5 and 6 for direction and speed. Orders of magnitude are roughly the same for the three pairs of buoys: for direction, the standard deviation decreases from $13^{\circ}-15^{\circ}$ at 10 min to $6^{\circ}-8^{\circ}$ at $12 \mathrm{~h}$; for speed, the standard deviation ranges from $1.2-1.4 \mathrm{~m} \mathrm{~s}^{-1}$ at $10 \mathrm{~min}$ to $0.6-0.7 \mathrm{~m} \mathrm{~s}^{-1}$ at $12 \mathrm{~h}$. From these results it appears that the standard deviation decreases by about $40 \%$ between $10 \mathrm{~min}$ and $6 \mathrm{~h}$ averaging durations, and only $10 \%$ between 6 and $12 \mathrm{~h}$, and so it seems reasonable to select an averaging duration of $6 \mathrm{~h}$ for buoy measurement comparisors.

\section{b. Results}

Statistical results comparing calibrated wind speed from the three buoys are given in Table 7 . The standard deviations of buoy wind speed differences are within $0.8 \mathrm{~m} \mathrm{~s}^{-1}$. Buoys 6 and 7 are in good agreement since only a $0.11 \mathrm{~m} \mathrm{~s}^{-1}$ mean difference is observed, which is rather satisfying, considering the accuracy of $a$ and $b$ calibration coefficients (section 5 ). In spite of the calibration, the speed data of these two buoys, equipped with three-cup anemometers, are still slightly higher (biases of 0.40 and $0.50 \mathrm{~m} \mathrm{~s}^{-1}$ ) than those of buoy 5 (propeller anemometer). An explanation might be that buoy 5 (Fig. 2) behaves much more like a spar buoy 

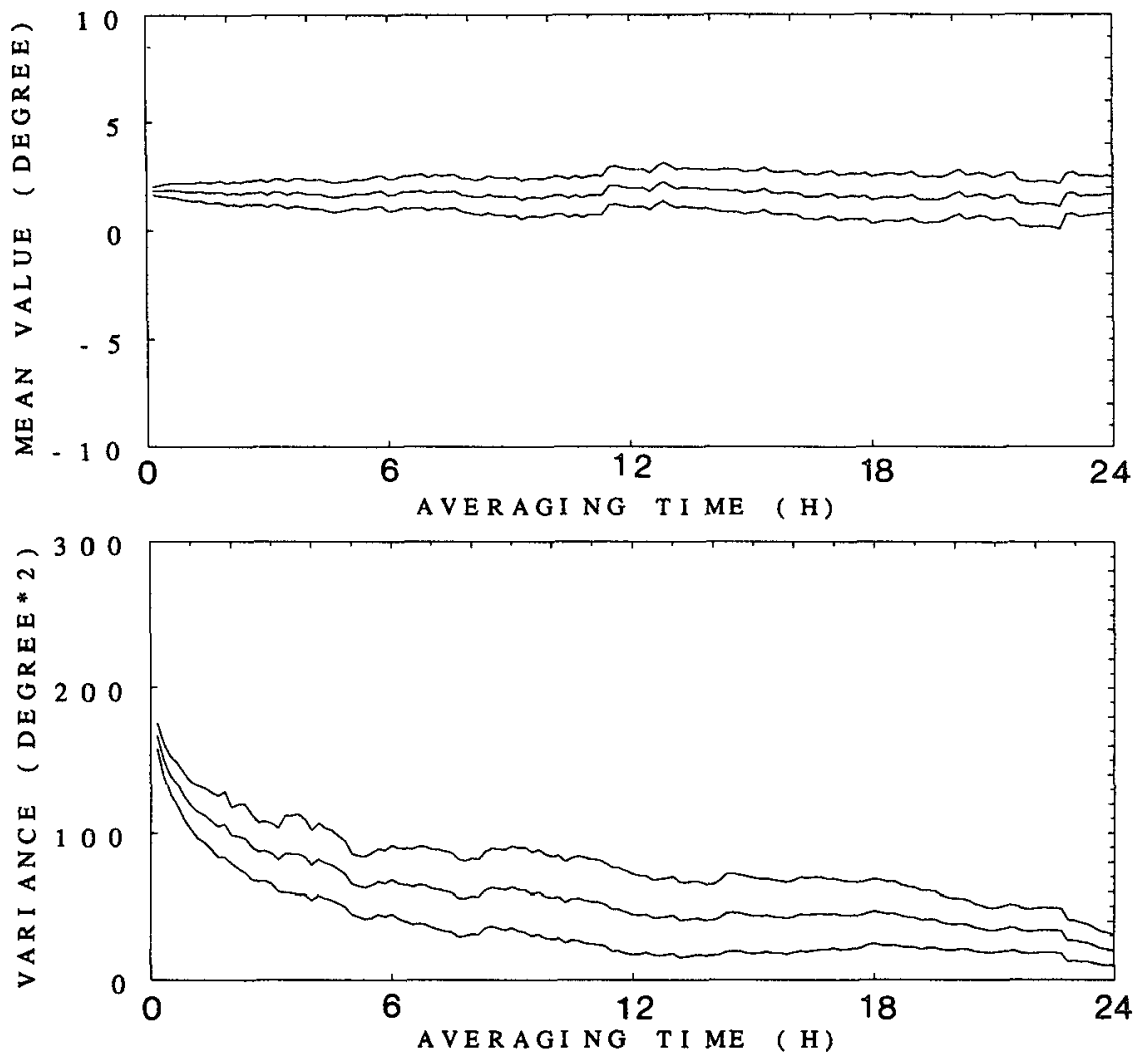

FIG. 18. Mean value and variance of wind direction differences between buoys 5 and 6 , as a function of averaging time.
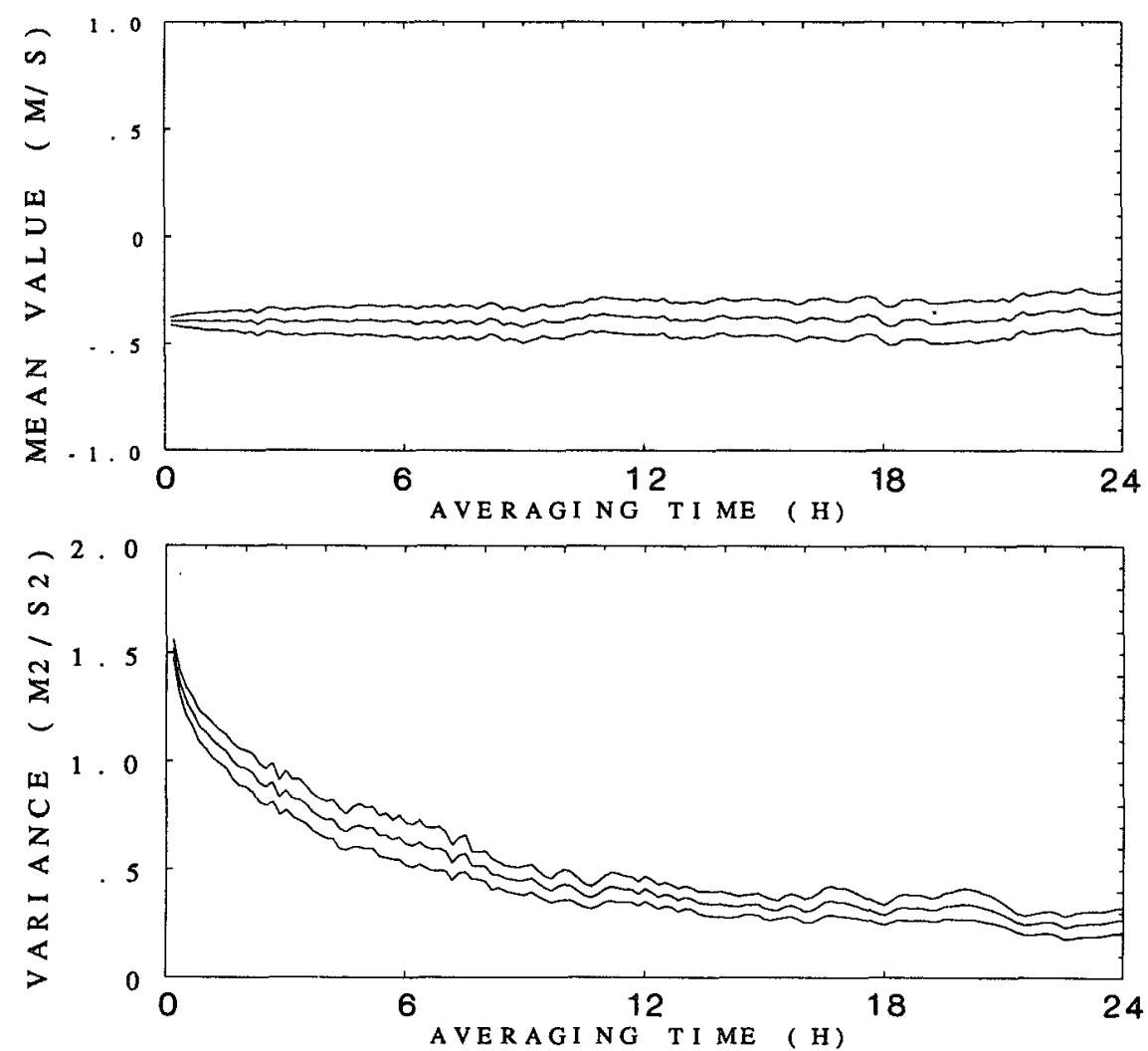

FIG. 19. Mean value and variance of wind speed differences between buoys 5 and 6 , as a function of averaging time. 
TABLE 5. Standard deviation of direction differences between buoys, expressed in degrees and in percentage of the standard deviation observed at $10 \mathrm{~min}$, for various averaging times.

\begin{tabular}{cccc}
\hline \hline Buoys & $\begin{array}{c}5-6 \\
{\left[0^{\circ}(\%)\right]}\end{array}$ & $\begin{array}{c}5-7 \\
{\left[0^{\circ}(\%)\right]}\end{array}$ & $\begin{array}{c}6-7 \\
{\left[{ }^{\circ}(\%)\right]}\end{array}$ \\
\hline $10 \mathrm{~min}$ & $12.9(100)$ & $14.7(100)$ & $14.8(100)$ \\
$1 \mathrm{~h}$ & $10.9(84)$ & $12.3(84)$ & $13.1(88)$ \\
$1 \mathrm{~h}$ & $9.3(72)$ & $10.8(73)$ & $9.9(67)$ \\
$6 \mathrm{~h}$ & $8.3(64)$ & $9.2(62)$ & $8.7(59)$ \\
$9 \mathrm{~h}$ & $8.0(62)$ & $7.8(53)$ & $8.2(56)$ \\
$12 \mathrm{~h}$ & $6.7(52)$ & $7.7(52)$ & $6.0(40)$ \\
Average & & & \\
$12-24 \mathrm{~h}$ & $6.3(49)$ & $7.4(50)$ & $7.2(49)$ \\
\hline
\end{tabular}

than buoys 6 and 7 (Fig. 4) and larger off-axis angles of these buoys result in overspeeding of the three-cup anemometer measurements, because of their vertical response (section 3). Nevertheless, the improvement due to the calibration is obvious, as shown by the results obtained without calibration, enclosed in parentheses in Table 7. Wind directions from all buoys are in good agreement with ship measurements (section 5) and the calibration correction is then very small. Mean values of calibrated direction differences between buoys are less than $5^{\circ}$, and standard deviations are less than $10^{\circ}$.

The above results on buoy performances are better than those reported by Weller et al. (1983), perhaps mainly because of a greater homogeneity among the TOSCANE-2 sensors and sampling schemes than for JASIN (Joint Air-Sea Interaction Program) 1978. Few comparisons between ship and buoy wind measurements are available. Reynolds (1982) compared the wind observations of the NOAA ship Oceanographer to measurements from a nearby buoy during the Storm Transfer and Response Experiment and obtained mean values of differences of $0.8 \mathrm{~m} \mathrm{~s}^{-1}$ for wind speed and $3.5^{\circ}$ for direction, with standard deviations of $1.2 \mathrm{~m} \mathrm{~s}^{-1}$ and $11^{\circ}$, respectively. Pierson (1990) inspected pairs of ship reports and buoy data separated by $100 \mathrm{~km}$ or less and found a poor quality of ship reports, made on a routine basis, even for ships equipped with anemometers of known height. The U.S. National Data Buoy

TABLE 6. Standard deviation of wind speed differences between buoys, expressed in meters per second and in percentage of the standard deviation observed at $10 \mathrm{~min}$, for various averaging times.

\begin{tabular}{llll}
\hline \hline Buoys & $\begin{array}{c}5-6 \\
{\left[\mathrm{~m} \mathrm{~s}^{-1}(\%)\right]}\end{array}$ & $\begin{array}{c}5-7 \\
{\left[\mathrm{~m} \mathrm{~s}^{-1}(\%)\right]}\end{array}$ & $\begin{array}{c}6-7 \\
{\left[\mathrm{~m} \mathrm{~s}^{-1}(\%)\right]}\end{array}$ \\
\hline $10 \mathrm{~min}$ & $1.23(100)$ & $1.39(100)$ & $1.31(100)$ \\
$1 \mathrm{~h}$ & $1.06(86)$ & $1.17(84)$ & $1.10(84)$ \\
$3 \mathrm{~h}$ & $0.93(75)$ & $1.01(73)$ & $0.99(76)$ \\
$6 \mathrm{~h}$ & $0.79(64)$ & $0.82(59)$ & $0.82(63)$ \\
$9 \mathrm{~h}$ & $0.67(64)$ & $0.72(52)$ & $0.69(53)$ \\
$12 \mathrm{~h}$ & $0.64(52)$ & $0.69(50)$ & $0.68(52)$ \\
Average & & & \\
$12-24 \mathrm{~h}$ & $0.56(45)$ & $0.66(47)$ & $0.63(48)$ \\
\hline
\end{tabular}

TABLE 7. Comparison of calibrated buoy wind speed mieasurements $\left(\mathrm{m} \mathrm{s}^{-1}\right)$, values enclosed in parentheses are results for noncalibrated data.

\begin{tabular}{cccccc}
\hline \hline Buoys & $N$ & Mean & $\begin{array}{c}\text { Standard } \\
\text { deviation }\end{array}$ & $A$ & $B$ \\
\hline $5-6$ & 122 & $-0.40(-1.35)$ & 0.79 & $1.08(1.10)$ & $-0.22(0.65)$ \\
$5-7$ & 123 & $-0.50(-0.72)$ & 0.82 & $1.10(0.95)$ & $-0.22(1.08)$ \\
$6-7$ & 123 & $-0.11(0.62)$ & 0.82 & $1.01(0.86)$ & $-0.01(0.54)$ \\
\hline
\end{tabular}

Center performed an extensive amount of field comparisons in 1984 and 1985 , to assess the performance of wind buoys. A comparison by Gilhousen (1985a) of several weeks (including storms events) of duplicate wind sensor data on a similar buoy (Bendix propeller anemometers) led to mean values of speed differences less than $0.2 \mathrm{~m} \mathrm{~s}^{-1}$, with standard deviations between 0.4 and $0.5 \mathrm{~m} \mathrm{~s}^{-1}$ (increasing with wind speed). For wind direction, the mean was less than $5^{\circ}$ and the standard deviation about $10^{\circ}$. These results agree with those obtained from TOSCANE-2 ship wind measurements. One month of data from two buoys, anchored $3.3 \mathrm{~km}$ apart, was also analyzed (Gilhousen 1986b) and mean values of differences were less than $0.2 \mathrm{~m} \mathrm{~s}^{-1}$ and $1.5^{\circ}$, with standard deviation of $0.78 \mathrm{~m} \mathrm{~s}^{-1}$ and $9.2^{\circ}$. Finally the author compared the $10-\mathrm{m}$-level corrected data from a fixed platform and a buoy $1.3 \mathrm{~km}$ away: mean value of speed differences was $0.59 \mathrm{~m} \mathrm{~s}^{-1}$, standard deviation $0.81 \mathrm{~m} \mathrm{~s}^{-1}$ for speed and $10.4^{\circ}$ for direction.

\section{Validation of Sein Island wind measurements}

For comparison, the mast data have been reduced to the measuring level of buoys. The height of the nuast anemometer was estimated about $16 \mathrm{~m}$ above mean sea level and, for correction, the tidal variation of the sea level was also taken into account. Over the experiment area the tide is mainly semidiurnal and the maximum-level amplitude during the experiment was about $5.3 \mathrm{~m}$. The variations of tidal level were computed by J. Garrett (personal communication). 'The data were also corrected for stability conditions, using the meteorological data of the CMM buoy at location M0.

A first comparison between mast and buoy wind speed data shows that the variances of measurement differences are much larger than those observed for buoy-to-buoy comparisons. For instance, for a 3-h averaging, variances are $2.4 \mathrm{~m}^{2} \mathrm{~s}^{-2}$ for mast-buoy 5 differences and $0.9 \mathrm{~m}^{2} \mathrm{~s}^{-2}$ for buoys 5 and 6 differences; these values become 1.8 and $0.4 \mathrm{~m}^{2} \mathrm{~s}^{-2}$ for a 12 -h average. A land effect was suspected to be responsible for this variance increase. The mast being located at the extreme west side of the island, which is narrow and mainly orientated along the east-west direction, the wind data were separated into two groups according to the direction: the east sector for directions between 

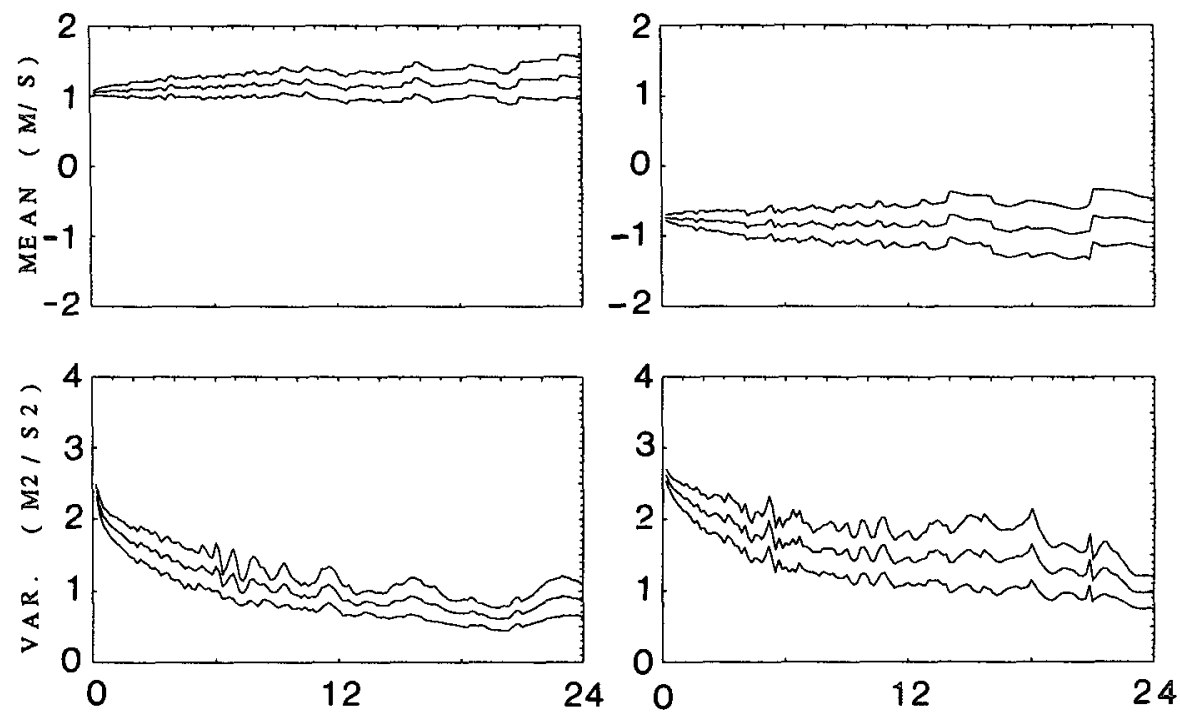

A VERAGI NG TIME ( H )

FIG. 20. Mean value and variance of wind speed differences between the mast and buoy 5 as a function of averaging time, for the west sector (left) and the east sector (right).

$0^{\circ}$ and $180^{\circ}$, and the west sector between $180^{\circ}$ and $360^{\circ}$. The east sector includes all the offshore winds and the west one contains only onshore winds. Results of comparisons to buoy 5 are shown in Fig. 20, for the two sectors: the variance and standard errors are less for the west sector than for the east one and there is a difference of about $1.8 \mathrm{~m} \mathrm{~s}^{-1}$ between mean values of buoy and mast wind speed differences relative to the two sectors. This means that for offshore winds (east sector) the variability increases and that the mast wind speed, relatively to the buoy, is less than for onshore winds (west sector). This is in agreement with a land effect: the surface roughness scale changes drastically from westerly winds ( sea) to easterly winds (land) and this results in an increase of mast wind speed variance and in a decrease of mast wind speed due to friction increase. As shown in Table 8, comparing 6-h-averaged wind speed data, differences between east and west sectors are observed similarly for the three buoys.

When considering only the west sector, mean values of speed differences show that the mast wind speed measurements are larger than those of the buoys and that significant differences exist among the buoys, from 0.38 to $1.32 \mathrm{~m} \mathrm{~s}^{-1}$, and so for standard deviation of differences, from 0.68 to $1.21 \mathrm{~m} \mathrm{~s}^{-1}$, the larger value being relative to buoy 5. Daniault et al. (1988) reported mean values less than $0.7 \mathrm{~m} \mathrm{~s}^{-1}$ and standard deviations between 0.8 and $1.3 \mathrm{~m} \mathrm{~s}^{-1}$, for comparison between a buoy, $6 \mathrm{~km}$ offshore, and coastal masts wind data from the TOSCANE-T experiment; the sea winds sector they considered $\left(110^{\circ}\right)$ was much more narrow than in our case study $\left(180^{\circ}\right)$ and distances between buoy and masts were shorter.
Differences between Sein and buoy data are induced by several factors. The first one is that the Sein anemometer has been calibrated only in steady conditions (wind tunnel) and not adjusted to the ship reference, and, as already indicated, the response in nature may be different. Then the crossbar's effect on the fixed anemometer is not at all smoothed (relative to direction) as it can be on a moving buoy. Finally, local topography in the vicinity of mast may influence the measurement according to wind direction, even for sea winds. Influence of these factors, combined with possible "geophysical" effects, can be seen in Fig. 10. The crossbar's effect is associated with the three relative minima observed for directions about $100^{\circ}, 230^{\circ}$, and $350^{\circ}$. The change of mean level between the two sectors $0^{\circ}-180^{\circ}$ and $180^{\circ}-360^{\circ}$ can be interpreted as the effect of friction over the island, resulting in a relatively lower mast wind speed. Local topography effect may perhaps explain the peak, for the three buoys, around $135^{\circ}$. But what is responsible for the difference of consistency among the data between the two direction sectors $40^{\circ}-$

TABLE 8. Mean values and standard deviations $\left(\mathrm{m} \mathrm{s}^{-1}\right)$ of differences between 6-h-averaged mast and buoy wind speed data, for west (W) and east (E) wind direction sectors.

\begin{tabular}{|c|c|c|c|c|c|c|}
\hline \multirow[t]{2}{*}{ Buoys } & \multicolumn{2}{|c|}{5} & \multicolumn{2}{|c|}{6} & \multicolumn{2}{|c|}{7} \\
\hline & W & $\mathrm{E}$ & W & E & W & E \\
\hline Mean & 1.32 & -0.54 & 0.79 & -0.88 & 0.38 & -0.49 \\
\hline $\begin{array}{l}\text { Standard } \\
\text { deviation }\end{array}$ & 1.21 & 1.30 & 0.68 & 1.48 & 0.88 & 1.26 \\
\hline
\end{tabular}


$90^{\circ}$ and $220^{\circ}-300^{\circ}$ ? For the first sector, comparisons to the three buoys give close results, when for the second sector buoy 5 (center location of the network) returns lower speed values than buoy 6 (south location) and buoy 7 (west location). As a result it does not seem feasible to calibrate accurately (better than $20 \%$ ) the mast wind speed data.

Comparison of buoy and mast wind direction measurements gives better results than for wind speed. Mean values of differences range between $3.1^{\circ}$ and $7.6^{\circ}$, and standard deviations between $7.7^{\circ}$ and $10.7^{\circ}$; the slope coefficients are very close to unity (within $2 \%$ ).

\section{Conclusion}

Analysis of ship, buoy, and island wind data of TOSCANE-2 experiment permits us to draw some conclusions about in situ wind data quality; which is useful for the calibration and validation of scatterometer data of the $E R S-1$ satellite, planned to be launched soon.

First, for high-quality measurements, preexperiment calibration of anemometers in wind tunnels is necessary but not sufficient because of measurement errors induced by the sensor responses to high-frequency fluctuations of wind speed, which are difficult to assess through laboratory tests. Then, even if the accuracy of the measurement of the absolute wind at sea is questionable (and mainly for speed), measurements from an array of buoys will be more efficient (for scatterometer validation) if surface data are "calibrated" against a reference and through cross comparisons between buoys. A dedicated ship can be used as a reference. Results obtained from two independent systems on board N/O Le Noroit were close together: standard deviations of $0.4 \mathrm{~m} \mathrm{~s}^{-1}$ and $5^{\circ}$ were observed on speed and direction differences, respectively, accuracy in direction being mainly limited by the resolution of one of the vane sensors. Using ship wind measurements as a reference implies strong operational constraints to get high-quality data. In particular, the ship must be maintained upwind in order that the flow disturbance by the ship superstructure be always the same and able to be corrected through previous tests at sea. Meteorological parameters necessary to adjust wind speed measurements from the ship to buoy levels or to a reference level are also needed, as well as an accurate measurement of the ship speed for absolute wind vector computation. In these conditions, the buoy measurements were calibrated using 20-min-averaged ship data, for separation distances between ship and buoys less than $3 \mathrm{~km}$. This permits us to significantly reduce errors on buoy measurements: maximum mean values of differences among the buoys were $0.5 \mathrm{~m} \mathrm{~s}^{-1}$ for speed and $4.3^{\circ}$ for direction, with corresponding standard deviations of $0.8 \mathrm{~m} \mathrm{~s}^{-1}$ and $9.2^{\circ}$. Such a ship calibration implies a long enough at-sea campaign to get a suffi- ciently wide range of measurements, but is neither realistic nor feasible for each buoy of the array (the nied for an array of in situ measurements for scatteromster calibration is a consequence of the ground swath size, $500 \mathrm{~km}$ for $E R S-1$, and of the dependence of the backscatter coefficient on incidence angle). As a consequence, the consistency of the data among the whole array will have to be tested through buoy-to-buoy comparisons. For this, the time length of wind averaging has to be carefully selected in order to match the distance between buoys to be compared and to filter out space variability. Analysis of TOSCANE-2 data showed that an average over at least $6 \mathrm{~h}$ is needed for distances of $25-35 \mathrm{~km}$ and that, even for a time average as long as $12 \mathrm{~h}$, particular events such as fronts or low wind speed situations (high variability of direction) have to be discarded from the dataset when testing the data consistency.

The above precision on wind measurements is compatible with the assessment of the $2 \mathrm{~m} \mathrm{~s}^{-i}$ and $20^{\circ}$ accuracy forseen for the $E R S-1$ scatterometer wind data. For the $E R S-1$ calibration phase, it is planned to assess the quality of surface data using methods presented above. The surface array will consist of ten buoys developed by the Norwegian company Oceanor, to IFREMER design specifications. Each buoy will be instrumented with one wave sensor and two independent wind-measuring devices using R. M. Young propellers. The buoys will be separated by $50-150 \mathrm{~km}$, covering an area $150 \times 450 \mathrm{~km}^{2}$, west of Norway. First tests of methods and instrumentations are performed on the data of the Rehearsal Experiment ERS-1 validation, Northern Europe (RENE) campaign performed over the Norwegian site in February and March 1990.

Acknowledgments. The author would like to thank people who participated in the TOSCANE-2 campaign and particularly R. Ezraty, the project manager of the TOSCANE program, J. P. Gouillou and S. Didailler for their participation in data acquisition and processing, and people of Centre de Meteorologie Marine who contributed to the buoy deployment and monitoring. The author would like also to thank captains and crews of N/O Thalia and Le Noroit (IFREMER), and of the service vessel George De Joly operated by Service Technique des Phares et Balises. The author is grateful to J. Garrett (Institut of Ocean Sciences, Sidney, B.C., Canada) for his comments on the subject and tidal data processing.

\section{REFERENCES}

Blanc, T. V., 1985: Variation of bulk derived surface flux, stability and roughness results due to the use of different transfert coefficient schemes. J. Phys. Oceanogr., 15, 650-669.

- 1986: Superstructure flow distortion corrections for wind speed and direction measurements made from Tarawa class (LHA1LHA5) ships. NRL Rep. 9005, Washington, D.C., 20 pp.

Burt, W. V., 1975: A comparison of the responses of identical cup 
anemometers mounted on a spar and a toroid buoy. J. Phys. Oceanogr., 5, 789-792.

Champagne-Philippe, M., 1989: Coastal wind in the transition from turbulence to mesoscale. J. Geophys. Res., 94(C6), 8055-8074.

Daniault, N., M. Champagne-Philippe, M. Camblan, and J. N. Thepaut, 1988: Comparison of sea surface wind measurements obtained from buoy, aircraft, and onshore masts during the TOSCANE T campaign. J. Atmos. Oceanic Technol., 5, 385-404.

Ezraty, R., and M. Ollitrault, 1985: Etude de l'algorithme d'estimation de la vitesse de frottement à la surface de la mer, ESTEC contract 6155-85-NL-BI, $55 \mathrm{pp}$. [Available from IFREMER, BP 70, 29280 Plouzane, France.]

Oceanol. Acta, Num. SP: Actes du Colloque Océanographie Spatiale, Brest, France, 23-32.

$\longrightarrow$, S. Didailler, and J. P. Gouillou, 1987: Operational use of a spear 'f' buoy, Atlantic Ocean, winter 1986-1987, campaign report-field evaluation, rapport DERO-87, 01-EO, IFREMER, BP 70, 29280 Plouzane, France, 40 pp.

Gilhousen, D. B., 1986a: A field evaluation of NDBC moored buoy winds, draft report. National Data Buoy Center NSTL, MS, 40 pp.

$\longrightarrow$ 1986b: An accuracy statement for meteorological measurements obtained from NDBC moored buoys. Proc. MDS '86 Marine Data Systems International Symp., New Orleans, 198-204.

Groupe Toscane, 1986: Vent et état de la mer dans la baie d'Audierne, campagne Toscane T. Campagnes Océanographiques Françaises, Vol. 4, 60 pp. [Available from IFREMER, BP 70, 29280 Plouzane, France.]

Kahma, K. K., and M. Lepparanta, 1981: On errors in wind speed observations on R/V Aranda. Geophysica, 17.1.2, 155-165.

Large, W. G., and S. Pond, 1981: Open ocean momentum flux measurements in moderate to strong winds. J. Phys. Oceanogr., 11, 324-336.

Lavanant, L., P. Queffeulou, and R. Ezraty, 1985: Sea wind fluctuations analysis. Third Int. Colloquium on Spectral Signatures of objects in Remote Sensing, Les Arcs, France, European Space Agency (ESA), Institut National de Recherche Agronomique (INRA) and Centre National d'Etudes Spatiales (CNES), 6366. [Doc. ESA SP-247.]

Long, A. E., 1985: Toward a C-band radar sea echo model for the ERS-I scatterometer. Third Int. Colloquium on Spectral Signatures of Objects in Remote Sensing, Les Arcs, France, European Space Agency (ESA), Institut National de Recherche Agronomique (INRA) and Centre National d'Etudes Spatiales (CNES), 29-34. [Doc. ESA SP-247.]

Maresca, C., and D. Favier, 1988: Essais en soufflerie de capteurs anémometriques de types coupelles (Debucourt) et anémo-girouette (Young). 38 pp. [Available from Institut de Mécanique des Fluides, 1 rue Honnorat, 13003 Marseille, France.]

Pierson, W. J., 1990: Examples of, reasons for, and consequences of the poor quality of wind data from ships for the marine boundary layer: Implications for remote sensing. $J$. Geophys. Res., 95(C8), 13 313-13 340.

Press, W. H., B. P. Flannery, S. A. Teukolsky, and W. T. Vetterling, 1986: Numerical Recipes. Cambridge University Press, 818 pp.

Queffeulou, P., S. Didailler, R. Ezraty, A. Bentamy, and J. P. Gouillou, 1988: Toscane-2 campaign report. IFREMER contribution, ESTEC contract 7138-87-NL-BI, 97 pp. [Available from IFREMER, BP 70, 29280 Plouzane, France.]

Reynolds, R. M., 1982: Comparison of surface meteorological observations from ship and toroid buoy in the North Pacific during STREX. J. Appl. Meteor., 21, 1032-1037.

Weller, R. A., R. E. Payne, W. G. Large, and W. Zenk, 1983: Wind measurements from an array of oceanographic moorings and from F/S Meteor during JASIN 1978. J. Geophys. Res., 88(C14), 9689-9705.

- D. L. Rudnick, R. E. Payne, J. P. Dean, N. J. Pennington, and R. P. Trask, 1990: Measuring near-surface meteorology over the ocean from an array of surface moorings in the subtropical convergence zone. J. Atmos. Oceanic Technol., 7, 85-103.

Wu, J., 1982: Wind stress coefficients over sea surface from breeze to hurricane. J. Geophys. Res., 87(C12), 9704-9706. 